\title{
1 CDK-Mediated Phosphorylation of FANCD2 Promotes Mitotic Fidelity
}

3 Juan A. Cantres-Velez a , Justin L. Blaize ${ }^{a}$, David A. Vierra ${ }^{a}$, Rebecca A.

4 Boisvert $^{\mathrm{a}}$, Jada M. Garzon ${ }^{\mathrm{b}}$, Benjamin Piraino ${ }^{\mathrm{a}}$, Winnie Tan, Andrew J.

5 Deans $^{\mathrm{c}}$, and Niall G. Howlett ${ }^{\mathrm{a},{ }^{*}}$

6

7 aDepartment of Cell and Molecular Biology, University of Rhode Island, Kingston,

8 Rhode Island, U.S.A

9 bDepartment of Medical Oncology, Dana-Farber Cancer Institute, Harvard Medical

10 School, Boston, MA

11 'Genome Stability Unit, St. Vincent's Institute of Medical Research, Fitzroy, VIC 3065,

12 Australia

$14{ }^{*}$ Corresponding author: Niall G. Howlett Ph.D., 379 Center for Biotechnology and Life

15 Sciences, 120 Flagg Road, Kingston, Rl, USA, Tel.: +1 401874 4306; Fax: +1 401874 


\section{Keywords}

Fanconi anemia, FANCD2, CDK phosphorylation, cell cycle, ubiquitination

\section{Abstract}

Fanconi anemia (FA) is a rare genetic disease characterized by increased risk for bone marrow failure and cancer. The FA proteins function together to repair damaged DNA.

A central step in the activation of the FA pathway is the monoubiquitination of the FANCD2 and FANCl proteins under conditions of cellular stress and during S-phase of the cell cycle. The regulatory mechanisms governing S-phase monoubiquitination, in particular, are poorly understood. In this study, we have identified a CDK regulatory phospho-site (S592) proximal to the site of FANCD2 monoubiquitination. FANCD2 S592 phosphorylation was detected by LC-MS/MS and by immunoblotting with a S592 phospho-specific antibody. Mutation of S592 leads to abrogated monoubiquitination of FANCD2 during S-phase. Furthermore, FA-D2 (FANCD2---) patient cells expressing S592 mutants display reduced proliferation under conditions of replication stress and increased mitotic aberrations, including micronuclei and multinucleated cells. Our findings describe a novel cell cycle-specific regulatory mechanism for the FANCD2 protein that promotes mitotic fidelity. 


\section{Author Summary}

Fanconi anemia (FA) is a rare genetic disease characterized by high risk for bone

marrow failure and cancer. FA has strong genetic and biochemical links to hereditary

41 breast and ovarian cancer. The FA proteins function to repair DNA damage and to

42 maintain genome stability. The FANCD2 protein functions at a critical stage of the FA

43 pathway and its posttranslational modification is defective in $>90 \%$ of FA patients.

44 However, the function, and regulation of FANCD2, particularly under unperturbed

45 cellular conditions, remains remarkably poorly characterized. In this study, we describe

46 a novel mechanism of regulation of the FANCD2 protein during S-phase of the cell

47 cycle. CDK-mediated phosphorylation of FANCD2 on S592 promotes the

ubiquitination of FANCD2 during S-phase. Disruption of this phospho-regulatory

mechanism results in compromised mitotic fidelity and an increase in mitotic

50 chromosome instability.

\section{Introduction}

53 Protection of the integrity of our genome depends on the concerted activities of

54 several DNA repair pathways that ensure the timely and accurate repair of damaged

55 DNA. These DNA repair pathways need to be tightly coordinated and regulated upon

56 cellular exposure to exogenous DNA damaging agents, as well as during the cell cycle.

57 Somatic disruption of the DNA damage response leads to mutation, genome instability 
58 and cancer. In addition, germline mutations in DNA repair genes are associated with hereditary diseases characterized by increased cancer risk and other clinical manifestations. Fanconi anemia (FA) is a rare genetic disease characterized by

61 congenital abnormalities, increased risk for bone marrow failure and cancer, and

62 accelerated aging [1]. FA is caused by germline mutations in any one of 23 genes. The

63 FA proteins function together in a pathway to repair damaged DNA and to maintain

64 genome stability. A major role for the FA pathway in the repair of DNA interstrand

65 crosslinks (ICLs) has been described [2]. comprising FANCA, FANCB, FANCC, FANCE, FANCF, FANCG, FANCL, UBE2T/FANCT, and the FA associated proteins. Monoubiquitination occurs following exposure to DNA damaging agents and during S-phase of the cell cycle $[3,4]$. to the formation of a closed ID2 clamp that encircles DNA [5, 6]. Moreover,

73 ubiquitinated ID2 (ID2-Ub) assembles into nucleoprotein filament arrays on doublestranded DNA [7]. The monoubiquitination of FANCD2 is necessary for efficient 

involved in mitotic DNA synthesis (MiDAS) during prophase and is present on the terminals of anaphase ultrafine bridges $[12,13]$. During the cell cycle FANCD2 monoubiquitination is maximal during S-phase and minimal during M-phase [4]. FANCD2 and FANCl are phosphorylated by the ATR and ATM kinases following exposure to DNA damaging agents, promoting their monoubiquitination [14-17]. However, in general, the function and regulation of FANCD2 and FANCI during the cell cycle remains poorly understood. progression, with CDK-mediated hyperphosphorylation of the retinoblastoma protein (pRb) being the primary mechanism of cell cycle regulation. CDKs are also known to regulate DNA repair during the cell cycle. Several protein components of the homologous recombination repair (HR), translesion DNA synthesis (TLS), non-

93 homologous end joining (NHEJ), and telomere maintenance pathways are CDK substrates [18]. For example, the BRCA2 protein is phosphorylated by CDK1 as cell progress towards mitosis. CDK-mediated phosphorylation of BRCA2 blocks interaction with RAD51 and thereby restricts HR DNA repair during M-phase [19]. Conversely, 
97 CDK1/2 phosphorylate the EXO1 nuclease to promote DNA strand resection and HR

98

100

101

102 repair during S-phase [20].

In this study we have examined the regulation of the FANCD2 protein by phosphorylation, specifically during the cell cycle. We show that FANCD2 is phosphorylated on S592, a putative CDK site, during S-phase but not during M-phase and is phosphorylated by CDK2 in vitro. Mutation of S592 as well as CDK inhibition disrupts S-phase FANCD2 monoubiquitination. Furthermore, we demonstrate that FAD2 (FANCD2 $\left.2^{-\prime}\right)$ patient cells stably expressing FANCD2 mutated at S592 display reduced growth under conditions of replication stress, an altered cell cycle profile, and increased genomic instability manifested as increased micronuclei, nucleoplasmic bridges, and aneuploidy. Our results uncover important mechanistic insight into the regulation of a key DNA repair/genome maintenance pathway under unperturbed cellular conditions.

\section{Results}

\section{FANCD2 is phosphorylated under unperturbed conditions and during S-phase of the}

\section{cell cycle}

To study the phosphorylation of the FANCD2 protein in the absence and presence of
DNA damaging agents, we performed a lambda-phosphatase assay with several cell lines following incubation in the absence or presence of the DNA crosslinking agent 
117 mitomycin C (MMC). Notably, we observed a large increase in FANCD2 mobility

118 following incubation of lysates with lambda-phosphatase even in the absence of MMC

119 in all cell lines examined (Fig. 1A). These results suggest that FANCD2 is subject to

120 extensive phosphorylation even in the absence of an exogenous DNA damaging

121 agent. A similar change in protein mobility was not observed for FANCl (Fig. 1A). To

122 determine if FANCD2 is subject to phosphorylation during the cell cycle, we performed

123 a double-thymidine block experiment causing an early S-phase arrest and analyzed

124 phosphorylation at regular time points following release. We observed maximal

125 phosphorylation of FANCD2 during S-phase of the cell cycle, with much less

126 phosphorylation observed as cells progressed through G2/M-and G1-phases of the cell

127 cycle (Fig. 1B). Again, we observed no appreciable change in FANCl mobility under the

128 same conditions, suggesting that $\mathrm{FANCl}$ is not subject to the same levels of

129 phosphorylation as FANCD2 during the cell cycle (Fig. 1B). Similar findings were

130 observed with U2OS cells (Fig. S1A and B). We also synchronized cells in M-phase

131 using nocodazole and, upon release, again observed maximal levels of FANCD2

132 phosphorylation during S-phase ( 15 h after release) (Fig. S1C and D). The FANCA

133 protein is a central component of the FA core complex, a multi-subunit ubiquitin ligase

134 that catalyzes the monoubiquitination of FANCD2 $[3,21]$. To determine if FANCD2

135 phosphorylation was dependent on its monoubiquitination, we performed a lambda-

136 phosphatase assay with asynchronous and early S-phase synchronized FA-A (FANCA $\left.{ }^{-/-}\right)$ 
137 and FANCA-complemented FA-A cells. S-phase FANCD2 phosphorylation was

138 observed in the absence of FANCA, albeit to a slightly lesser extent than in cells

139 FANCA-complemented FA-A cells (Fig. 1C). These results suggest that S-phase

140 phosphorylation is coupled to, but not dependent upon, the monoubiquitination of

141 FANCD2.

\section{FANCD2 is a CDK substrate}

144 Phosphorylation of FANCD2 during the cell cycle suggested a role for cyclin-

145 dependent kinases (CDKs) in the regulation of FANCD2. CDKs phosphorylate serine or

146 threonine residues in the consensus sequence $\left[S / T^{\star}\right] P X[K / R]$, and several DNA repair

147 proteins are known CDK substrates, including BRCA2, FANCJ, and CtIP [19, 22, 23].

148 Both FANCD2 and FANCI have several putative CDK phosphorylation sites with

149 varying degrees of conservation (Fig. S2A and B). To begin to assess the role of CDKs

150 in the regulation of FANCD2, we performed a double-thymidine block in the absence

151 and presence of the CDK inhibitors purvalanol A and SNS-032. At the concentrations

152 tested, treatment with both inhibitors resulted in a significant reduction in the levels of

153 FANCD2 and FANCI monoubiquitination observed after double-thymidine arrest and a

154 modest reduction in FANCD2 phosphorylation (Fig. 2A). Reduced FANCD2

155 phosphorylation was also observed upon incubation with other CDK inhibitors and

156 upon short-term exposure to purvalanol A (Fig. S2C and D). To determine if FANCD2 is 
157 a CDK substrate, we immunoprecipitated FANCD2 from FA-D2 (FANCD2-/) patient

158 cells stably expressing V5-tagged LacZ or FANCD2, and probed immune complexes

with a pan anti-pS/T-CDK antibody. An immune reactive band was detected in immune

160 complexes from cells expressing FANCD2 and not LacZ (Fig. 2B), suggesting that

161 FANCD2 is a CDK substrate. We also performed an in vitro CDK kinase assay with

162 CDK2-Cyclin A and full length FANCD2 purified from High Five insect cells [24]. CDK-

163 mediated FANCD2 phosphorylation was already evident upon purification from insect

164 cells (Fig. 2C). Following dephosphorylation with lambda phosphatase, we observed a

165 concentration-dependent increase in FANCD2 phosphorylation upon incubation with

166 CDK2-Cyclin A. These results indicate that FANCD2 is a CDK substrate and suggest

167 that FANCD2 monoubiquitination may be regulated or coupled with CDK

168 phosphorylation.

FANCD2 is phosphorylated on S592 during S-phase of the cell cycle

171 To map the in vivo sites of FANCD2 phosphorylation, we immunoprecipitated

172 FANCD2 from asynchronous U2OS cells stably expressing 3xFLAG-FANCD2 under

173 stringent conditions, and performed phosphoproteomic analysis using LC-MS/MS (Fig.

$1743 \mathrm{~A}$ and $\mathrm{B})$. Under these conditions, we observed the phosphorylation of multiple sites

175 including the previously detected ATM/ATR phosphorylation sites S1401 and S1404

176 (Table 1) [17]. We also detected phosphorylation of the putative CDK site S592 (Table 

analysis using LC-MS/MS (Fig. 3C-F). Under these conditions, we detected play an important regulatory function during S-phase (Fig. 3F).

\section{Mutation of S592 disrupts S-phase FANCD2 monoubiquitination}


evidenced by equal protein expression levels and intact monoubiquitination following MMC exposure (Fig. S3A). Previous studies have shown that FANCD2 undergoes monoubiquitination as cells progress through S-phase of the cell cycle [4]. To analyze the effects of S592 mutation on S-phase FANCD2 monoubiquitination, cells were subject to a double-thymidine block, and FANCD2 monoubiquitination was analyzed upon release. Consistent with previous studies, we observed an increased in monoubiquitination of wild-type FANCD2 as cells progressed through S-phase (Fig. 4C). In contrast, S-phase monoubiquitination was markedly attenuated for both FANCD2-S592A and FANCD2-S592D (Fig. 4C). We also analyzed levels of the mitotic marker H3 pS10 in these cells. Compared to cells expressing wild-type FANCD2, we observed persistent levels of $\mathrm{H} 3$ pS10 in FA-D2 cells expressing empty vector and the FANCD2-S592A mutant (Fig. 4C). We observed a similar phenotype of elevated H3 pS10 in HeLa FANCD2\%- cells generated by CRISPR-Cas9 gene editing (Fig. S3B-D) [25]. In contrast to cells expressing empty vector and the FANCD2-S592A mutant, we observed a more rapid disappearance of H3 pS10 in cells expressing FANCD2-S592D (Fig. 4C). In addition, FACS analysis of FA-D2 patient cells expressing empty vector and the S592 variants upon release from double-thymidine block indicated a higher percentage of cells in G2/M at earlier time points, compared to cells expressing FANCD2-WT (Fig. S3E). Taken together, these results demonstrate that mutation of 
216 FANCD2 S592 disrupts S-phase monoubiquitination and leads to altered G2-M cell

217 cycle progression.

Mutation of FANCD2 S592 leads to decreased proliferative capacity and increased

221 To assess the functional impacts of mutation of FANCD2 S592, we monitored the

222 proliferation of FA-D2 patient cells stably expressing FANCD2-WT and the S592

223 variants in the presence of low concentrations of DNA damaging agents for prolonged

224 periods using the xCELLigence real time cell analysis system. The $x$ CELLigence system

225 enables the analysis of cellular phenotypic changes by continuously monitoring

226 electrical impedance. Impedance measurements are displayed as the cell index, which

227 provides quantitative information about the biological status of the cells, including cell

228 number, cell viability, and cell morphology. Compared to cells expressing FANCD2-

229 WT, cells expressing empty vector and the S592 variants exhibited reduced

230 proliferation when cultured in the presence of low concentrations of the DNA

231 polymerase inhibitor aphidicolin (APH) (Fig. 5A and S5A). In contrast, mutation of

232 FANCD2 S592 had no discernible impact on growth in the presence of low

233 concentrations of mitomycin C (MMC) (Fig. 5A and S5A). We also analyzed growth in

234 the presence of the CDK1 inhibitor RO3306. CDK1 inhibition resulted in reduced cell

235 proliferation in cells expressing FANCD2-WT and the S592A variant compared to cells 
236 expressing empty vector or the S592D variant (Fig. S5B and C). Next, we examined the

237 effects of mutation of S592 on levels of mitotic aberrations. Compared to FA-D2 cells expressing wild-type FANCD2, we observed increased levels of micronuclei,

239 nucleoplasmic bridges, and bi- and multi-nucleated cells in FA-D2 cells expressing the

240 S592 variants (Fig. 5B). Elevated levels of mitotic aberrations were also observed in FA-

241 D2 cells expressing FANCD2-K561R, which cannot be monoubiquitinated (Fig. 5B).

242 Taken together, these results indicate that S592 phosphorylation is functionally

243 necessary to ensure mitotic fidelity and chromosome stability under non-stressed

244 conditions.

\section{Discussion}

247 In this study, we have investigated the posttranslational regulation of the central FA pathway protein FANCD2 largely under unperturbed conditions. The majority of studies to date have focused on the posttranslational regulation of FANCD2 and

251 observed that FANCD2 undergoes extensive phosphorylation during the cell cycle

252 and, in particular, during S-phase of the cell cycle. Notably, in contrast, FANCl - a

253 FANCD2 paralog - does not appear to be subject to the same degree of

254 phosphorylation during the cell cycle. We have also determined that FANCD2 is

255 phosphorylated on S592 by CDK2-Cyclin A during S-phase using several approaches, 
256 including phosphoproteomic analysis of FANCD2 immune complexes from

257 synchronized cell populations and immunoblotting with a S592 phospho-specific

258 antibody. Previous studies have shown that FANCD2 is monoubiquitinated as cells

259 traverse S-phase, and this has been shown to contribute to the protection of stalled

260 replication forks from degradation $[4,11]$. Here we show that mutation of S592, or CDK

261 inhibition, abrogates S-phase monoubiquitination, strongly suggesting that S592

262 phosphorylation primes FANCD2 for ubiquitination during S-phase. Recent studies

263 have established that the FANCL RING E3 ubiquitin ligase allosterically alters the active

264 site of the UBE2T E2 ubiquitin-conjugating enzyme to promote site-specific

265 monoubiquitination of FANCD2 [27]. Specifically, FANCL binding to UBE2T exposes a

266 basic triad of the UBE2T active site, promoting favorable interactions with a conserved

267 acidic patch proximal to K561, the site of ubiquitination [27]. We speculate that S592

268 phosphorylation may augment interaction with the basic active site of UBE2T.

269 Alternatively, S592 phosphorylation may inhibit FANCD2 de-ubiquitination by USP1, in

270 a manner similar to that previously reported for the FANCI S/TO cluster [15].

271 Our studies further emphasize the critical nature of coordinated posttranslational

272 modification of FANCD2. Several studies have previously established intricate

273 dependent and independent relationships between FANCD2 monoubiquitination and

274 phosphorylation. For example, the ATM kinase phosphorylates FANCD2 on several

275 S/TO motifs following exposure to ionizing radiation, e.g. S222, S1401, S1404, and 
S1418 [17] - phosphorylation of S1401 and S1404 were also detected under modifications, including phosphorylation at other sites, e.g. S1401 and S1404 detected in this study, also contribute to the regulation of FANCD2 during the cell cycle. 
296 during S-phase [31]. While a role for FANCD2 in HR has been established [32], it

297 remains to be determined if CDK-mediated FANCD2 S592 phosphorylation promotes

298 HR or other related functions. For example, FANCD2 has been shown to have a DNA

299 repair-independent role in protecting stalled replication forks from MRE11-mediated

300 degradation [11]. We have also previously established an important role for FANCD2 in

301 the maintenance of CFS stability: In the absence of FANCD2, CFS replication forks stall

302 at a greater frequency, a likely consequence of persistent toxic R-loop structures,

303 leading to visible gaps and breaks on metaphase chromosomes [8, 10, 33, 34]. Under

304 conditions of replication stress, CFSs can remain unreplicated until mitosis where

305 replication can be completed through a process referred to as mitotic DNA synthesis

306 (MiDAS), a POLD3- and RAD52-dependent process that shares features with break-

307 induced DNA replication (BIR) $[35,36]$. FANCD2 has been shown to play a role in

308 MiDAS $[12,13]$. Defects in - or an overreliance upon - this process are likely to lead to

309 chromosome missegregation and mitotic defects, as we have observed upon mutation

310 of S592. Increased mitotic aberrations have previously been observed in primary

311 murine FA pathway-deficient hematopoietic stem cells and FA-patient derived bone

312 marrow stromal cells [9]. Taken together, our results support a model whereby CDK-

313 mediated S592 phosphorylation promotes efficient S-phase monoubiquitination,

314 ensuring the efficient and timely completion of CFS replication and mitotic

315 chromosome stability. A greater understanding of the function and regulation of the FA 
316 pathway under physiologically relevant non-stressed conditions will provide greater

317 insight into the pathophysiology of this disease and ultimately lead to improved

318 therapeutic options for FA patients.

\section{Materials and Methods}

\section{Cell culture and generation of mutant cell lines}

322 HeLa cervical carcinoma and U2OS osteosarcoma cells were grown in Dulbecco's

323 modified Eagle's medium (DMEM) supplemented with 10\% v/v FBS, L-glutamine and

324 penicillin/streptomycin. HeLa FANCD2 ${ }^{-/-}$cells generated by CRISPR-Cas9 were

325 generously provided by Martin Cohn at the University of Oxford [25]. 293FT viral

326 producer cells (Invitrogen) were cultured in DMEM containing 12\% v/v FBS, $0.1 \mathrm{mM}$

327 non-essential amino acids (NEAA), 1\% v/v L-glutamine, $1 \mathrm{mM}$ sodium pyruvate and $1 \%$

$328 \mathrm{v} / \mathrm{v}$ penicillin/streptomycin. PD20 FA-D2 (FANCD2 ${ }^{\mathrm{hy} /-}$ ) patient cells were purchased

329 from Coriell Cell Repositories (Catalog ID GM16633). These cells harbor a maternally

330 inherited A-G change at nucleotide 376 that leads to the production of a severely

331 truncated protein, and a paternally inherited missense hypomorphic (hy) mutation

332 leading to a R1236H change. PD20 FA-D2 cells were stably infected with

333 pLenti6.2/V5-DEST (Invitrogen) harboring wild-type or mutant FANCD2 cDNAs. Stably

334 infected cells were grown in DMEM complete medium supplemented with $2 \mu \mathrm{g} / \mathrm{ml}$

335 blasticidin. 
Triton X-100, 200 mM NaCl, 5 mM EDTA, $2 \mathrm{mM} \mathrm{Na}_{3} \mathrm{VO}_{4}$, Protease inhibitors (Roche),

\section{Cell cycle FANCD2 immunoprecipitation}

353 S-phase and M-phase synchronized populations of HeLa cells were lysed in lysis buffer

354 (20 mM HEPES, pH 7.9, $1.5 \mathrm{mM} \mathrm{MgCl}_{2}, 400 \mathrm{mM} \mathrm{KCl}, 0.2 \mathrm{mM}$ EDTA, 20\% glycerol, 0.1

$355 \mathrm{mM}$ DTT, 0.1\% NP-40, 1 mM PMSF and complete protease inhibitors). 100 units of 
356 benzonase was added per $100 \mu \mathrm{L}$ of lysis buffer. Protein $\mathrm{G}$ magnetic beads

357 (Dynabeads, Novex) were crosslinked with anti-FANCD2 (NB100-182, Novus

Biologicals) antibody. An equal volume of no salt buffer (20 mM HEPES, pH7.9, 1.5 mM

$\mathrm{MgCl}_{2}, 0.2 \mathrm{mM} \mathrm{KCl}, 0.2 \mathrm{mM}$ EDTA, $0.1 \mathrm{mM}$ DTT, $0.1 \%$ NP-40, plus complete protease

360

361

362

363

364

365

inhibitors) was added to $2 \mathrm{mg}$ of whole cell lysate. Samples were resuspended in anti-

FANCD2-bound beads rotating at $4^{\circ} \mathrm{C}$ for $4 \mathrm{~h}$. Beads were washed in wash buffer (20

mM HEPES, pH 7.9, 1.5 mM MgCl $2,0.2$ mM KCl, $300 \mathrm{mM} \mathrm{KCl,} 10 \%$ glycerol, $0.2 \mathrm{mM}$

EDTA, $0.1 \mathrm{mM}$ DTT, $0.1 \%$ NP-40, plus complete protease inhibitor). The samples were

eluted in urea elution buffer (8 $\mathrm{M}$ urea, $1 \mathrm{mM} \mathrm{Na}_{3} \mathrm{VO}_{4}, 2.5 \mathrm{mM} \mathrm{Na}_{2} \mathrm{H}_{2} \mathrm{P}_{2} \mathrm{O}, 1 \mathrm{mM} \beta$ -

glycerophosphate and 25 mMHEPES, $\mathrm{pH}$ 8.0). Silver staining was performed to

visualize the IP and FANCD2 pulldown was confirmed by western blot. Samples were

sent for LC-MS/MS analysis at the COBRE Center for Cancer Research Development

Proteomics Core at Rhode Island Hospital.

\section{Lambda phosphatase assay}

Cells were harvested and pellets were split into two, lysed in either lambda

phosphatase lysis buffer (50 mM Tris- $\mathrm{HCl}$ pH 7.5, $150 \mathrm{mM} \mathrm{NaCl,} 0.1 \mathrm{mM}$ EGTA, $1 \mathrm{mM}$

dithiothreitol, $2 \mathrm{mM} \mathrm{MnCl}$, 0.01\% Brij35, 0.5\% NP-40, and protease inhibitor) or

lambda phosphatase buffer with the addition of phosphatase inhibitors, $2 \mathrm{mM} \mathrm{Na}_{3} \mathrm{VO}_{4}$

and $5 \mathrm{mM} \mathrm{NaF}$ for $15 \mathrm{~min}$ at $4^{\circ} \mathrm{C}$ followed by sonication for $10 \mathrm{~s}$ at $10 \%$ amplitude 
376 using a Fisher Scientific Model 500 Ultrasonic Dismembrator. Lysates were incubated

377 with or without $30 \mathrm{U}$ of lambda phosphatase $1 \mathrm{~h}$ at $30^{\circ} \mathrm{C}$.

379 Immunoblotting

380 For immunoblotting analysis, cell pellets were washed in PBS and lysed in $2 \% \mathrm{w} / \mathrm{v}$

381 SDS, $50 \mathrm{mM}$ Tris-HCl, $10 \mathrm{mM}$ EDTA followed by sonication for $10 \mathrm{~s}$ at $10 \%$ amplitude.

382 Proteins were resolved on NuPage 3-8\% w/v Tris-Acetate or $4-12 \%$ w/v Bis-Tris gels

383 (Invitrogen) and transferred to polyvinylidene difluoride (PVDF) membranes. The

384 following antibodies were used: rabbit polyclonal antisera against CHK1 (2345, Cell

385 Signaling), CHK1 pS345 (2345, Cell Signaling), cyclin A (SC751, Santa Cruz), CDC2

386 pY15 (4539,Cell Signaling), FANCD2 (NB100-182; Novus Biologicals), FANCI (A301-

387 254A, Bethyl), FLAG (F7425, Sigma), H3 pS10 (9701, Cell Signaling), pan pS/T-CDK

388 (9477, Cell Signaling), and V5 (13202, Cell Signaling), and mouse monoclonal antisera 389 against a-tubulin (MS-581-PO, Neomarkers).

392 The FANCD2 S592A and S592D cDNAs were generated by site-directed mutagenesis 393 of the wild type FANCD2 cDNA using the Quikchange Site-directed Mutagenesis Kit 394 (Stratagene). The forward (FP) and reverse (RP) oligonucleotide sequences used are as 395 follows: S592A FP 5'- CGGCAGACAGAAGTGAAGCACCTAGTTTGACCCAAG-3'; 
S592A RP 5'-CTTGGGTCAAACTAGGTGCTTCACTTCTGTCTGCCG-3'; S592D FP 5'-

FANCD2 cDNA sequences were TOPO cloned into the pENTR/D-TOPO (Invitrogen)

400 entry vector, and subsequently recombined into the pLenti6.2N5-DEST (Invitrogen) destination vector and used to generate lentivirus for the generation of stable cell

402 lines.

403

404

\section{Immunofluoresence microscopy}

Hela or Hela FANCD2 ${ }^{-/}$generated by CRISPR-Cas9 were seeded in at a density of $2 \mathrm{x}$

411 incubated with mouse-anti H3 pS10 (9706, Cell Signaling) and rabbit-anti-FANCD2.

412 Cells were washed with PBS and incubated in secondary goat-anti-mouse Alexa Fluor

413594 and donkey-anti-rabbit Alexa Fluor 488 in ABD for 1 h. Cells were washed in PBS

414 and stained with 4',6-diamidino-2-phenylindole dihydrochloride (DAPI, Vector

415 Laboratories). 


\section{Cell-cycle synchronization}

418 For early S-phase arrest, cells were synchronized by the double-thymidine block

419 method. Cells were seeded in $10 \mathrm{~cm}^{2}$ dishes and treated with $2 \mathrm{mM}$ thymidine

420 (226740050, Acros Organics) for 18 h. Cells were washed with PBS and released into

421 thymidine-free media for $10 \mathrm{~h}$ following by a second incubation in $2 \mathrm{mM}$ thymidine for

$42218 \mathrm{~h}$. Cells were washed twice with phosphate-buffered saline (PBS) and released into

423 thymidine-free media. For M-phase arrest, cells were synchronized using the mitotic

424 shake-off method. HeLa cells were seeded in $10 \mathrm{~cm}^{2}$ dishes. Cells were treated with

$425100 \mathrm{ng} / \mathrm{mL}$ of nocodazole (SML1665, Sigma) at 80-90\% confluency for $15 \mathrm{~h}$. Mitotic

426 cells were collected by the shake off method and re-plated in nocodazole-free media

427 for cell cycle progression analysis. For late G2-phase arrest, cells were synchronized by

428 reversible inhibition of CDK1 (Vassilev 2006). Cells were seeded in $10 \mathrm{~cm}^{2}$ dishes and

429 treated with $6 \mu \mathrm{M}$ R03306 (15149, Cayman Chemicals) for 16 h. Cells were washed

430 with PBS and released into fresh media without R03306.

\section{Cell cycle analysis by FACS}

433 Cells were fixed in ice cold methanol, washed in PBS and incubated in $50 \mu \mathrm{g} / \mathrm{mL}$

434 propidium iodide (PI) (Sigma) and $30 \mathrm{U} / \mathrm{mL}$ RNase A for $10 \mathrm{~min}$ at $37^{\circ} \mathrm{C}$, followed by 
435 analysis using a BD FACSVerse flow cytometer. The percentages of cells in G1, S, and

436 G2/M were determined by analyzing PI histograms with FlowJo V10.2 software.

\section{In-vitro CDK phosphorylation assay}

439 Purified FANCD2 CDK2-Cyclin A proteins were a generous gift from Andrew Deans at 440 the University of Melbourne. In order to remove any previous phosphorylation $2 \mu \mathrm{g}$ of

441 protein were incubated with $100 \mathrm{U}$ of lambda phosphatase, $10 \mathrm{mM}$ protein

442 metallophosphatases (PMP) and $10 \mathrm{mM} \mathrm{MnCl}_{2}$ at $30^{\circ} \mathrm{C}$ for $30 \mathrm{~min}$. For the

443 phosphorylation reaction, each reaction tube was composed of the following reagents

444 in this specific order: 10x CDK kinase buffer (250 mM Tris pH 7.5, $250 \mathrm{mM}$

445 glycerophosphate, 50 mM EGTA, $100 \mathrm{mM} \mathrm{MgCl}_{2}$ ), $2 \mu \mathrm{g}$ of protein, $15 \mathrm{nM}$

446 CDK2:Cyclin A, and $20 \mu \mathrm{M}$ ATP. Samples were incubated at $30^{\circ} \mathrm{C}$ for 30 min and the

447 reaction was stopped by adding $10 \mu \mathrm{L}$ of $10 \% \beta$-mercaptoethanol in $4 \mathrm{x}$ LDS buffer.

\section{Cell proliferation assay}

450 For cell proliferation assays we performed electrical impedance analysis using the

451 xCELLigence RTCA DP system from Acea Biosciences. Cells were seeded in

452 polyethylene terephthalate (PET) E-plates (300600890, Acea Biosciences). Cells were

453 incubated in the absence or presence of $0.4 \mu \mathrm{M}$ aphidicolin (APH) or $20 \mathrm{nM}$ mitomycin 
$454 \mathrm{C}(\mathrm{MMC})$ for $120 \mathrm{~h}$. Electrical impedance measurements were taken every 15 min over

455 the course of the incubation. Statistical analysis was performed using R.

\section{Acknowledgements}

458 We thank members of the Howlett, Camberg, and Dutta laboratories for critical

459 discussions. We thank Andrew A. Deans and Winnie Tan at the University of Melbourne

460 for purified proteins and Martin A. Cohn at the University of Oxford for HeLa FANCD2-/-

461 cells. This work was supported by NIH/NIGMS grant R01HL149907 (N.G.H.), an

462 American Society of Hematology Bridge Grant (N.G.H.); Rhode Island IDeA Network of

463 Biomedical Research Excellence (RI-INBRE) grant P20GM103430 from the National

464 Institute of General Medical Sciences; and Rhode Island Experimental Program to

465 Stimulate Competitive Research (RI-EPSCoR) grant \#1004057 from the National

466 Science Foundation. We declare that we have no conflicts of interest. 
$470 \quad$ Figure Legends

471 Figure 1. FANCD2 is phosphorylated under non-stressed conditions and during S-

472 phase of the cell cycle

473 (A) HeLa, U2OS and COS-7 cells were incubated with or without 200 nM MMC for 24

474 h. Cells were harvested and lysed in lambda phosphatase lysis buffer, incubated in the

475 absence or presence of lambda phosphatase, and the indicated proteins were

476 analyzed by immunoblotting. (B) HeLa cells were synchronized at the G1/S boundary

477 by a double-thymidine block and released into thymidine-free media. Cells were lysed

478 in lambda phosphatase buffer, incubated in the presence or absence of lambda

479 phosphatase, and lysates analyzed by immunoblotting. For cell cycle stage analysis,

480 cells were fixed, stained with propidium iodide and analyzed by flow cytometry. (C)

481 FA-A $\left(\mathrm{FANCA}^{-/}\right)$and FANCA-complemented FA-A cells were synchronized at the G1/S

482 boundary by a double-thymidine block and released into thymidine-free media. Cells

483 were harvested, lysed in lambda phosphatase buffer, incubated in the presence or

484 absence of lambda phosphatase, and analyzed by immunoblotting.

486 Figure S1. Phosphorylation of FANCD2 during S-phase of the cell cycle

487 (A) U2OS cells were synchronized at the G1/S boundary by a double-thymidine block

488 and released into thymidine-free media. Cells were harvested, lysed in lambda

489 phosphatase buffer and incubated in the presence or absence of lambda 
490 phosphatase. Samples were analyzed by immunoblotting. (B) Cells were fixed, stained

491 with propidium iodide and analyzed by flow cytometry to determine cell cycle stage.

492 (C) HeLa cells were synchronized in M-phase with a nocodazole block. Mitotic cells

493 were physically detached by the shake-off method and released into nocodazole-free

494 media. Cells were harvested, lysed in lambda phosphatase buffer and incubated in the

495 presence or absence of lambda phosphatase. Samples were analyzed by

496 immunoblotting. (D) Cells were fixed, stained with propidium iodide and analyzed by

497 flow cytometry to determine cell cycle stage.

\section{Figure 2. FANCD2 is a CDK substrate}

500

(A) HeLa cells were synchronized at the G1/S boundary by a double-thymidine block

501 performed in the absence or presence of the CDK inhibitors Purvalanol A (PURV-A) or

SNS-032. Cells were lysed in lambda phosphatase buffer, incubated in the absence or

503 presence of lambda phosphatase, and analyzed by immunoblotting. Cells were also

504 fixed, stained with propidium iodide and analyzed by flow cytometry to determine cell

505 cycle stage. (B) FA-D2 (FANCD2-/) cells stably expressing LacZ-V5 or FANCD2-V5

506 were immunoprecipitated with anti-V5 agarose and immune complexes were

507 immunoblotted with anti-FANCD2 and anti-pS-CDK antibodies. (C) Purified FANCD2

508 was incubated in the absence (-) or presence (+) of lambda phosphatase followed by

509 incubation with increasing concentrations of CDK2-Cyclin A and ATP at $30^{\circ} \mathrm{C}$ for 30 
510 min. Samples were immunoblotted with a pan anti-pS-CDK antibody or stained with

511 SimplyBlue SafeStain.

\section{Figure S2. FANCD2 is a CDK substrate}

514 (A-B) Shown is an alignment of mouse, human, and chicken FANCD2 (A) and FANCl

515 (B) amino acid sequences using the T-Coffee server, with the secondary structure of

516 mouse FANCD2 or FANCI illustrated. Putative CDK phosphorylation sites are shaded

517 in yellow. (C) HeLa cells were incubated in the absence (NT) or presence of $10 \mu \mathrm{M}$

518 olumucine (Olo), $10 \mu \mathrm{M}$ olomucine II (Olo II), $10 \mu \mathrm{M}$ purvalanol A (Pur), $10 \mu \mathrm{M}$ RO3306

519 (Ro) and $20 \mu \mathrm{M}$ roscovitine (Rosc) for $24 \mathrm{~h}$. Whole cell lysates were incubated in the

520 absence or presence of lambda phosphatase and analyzed by immunoblotting. (D)

521 HeLa cells were treated with $10 \mu \mathrm{M}$ purvalanol A for the indicated times, lysates were

522 incubated in the absence or presence of lambda phosphatase, and analyzed by

523 immunoblotting.

525 Figure 3. FANCD2 is phosphorylated on S592 during S-phase

526 (A-B) FANCD2 was immunoprecipitated from U2OS cells stably expressing 3xFLAG-

527 FANCD2 under stringent conditions using anti-FLAG agarose. Immune complexes

528 were analyzed by immunoblotting using anti-FLAG and anti-FANCD2 antibodies (A),

529 and by staining with SimplyBlue SafeStain (B). Immunoprecipitated FANCD2 bands 
530 were combined and subjected to phosphoproteomic analysis using LC-MS/MS. (C)

531 HeLa cells were synchronized in M-phase by nocodazole block. Mitotic cells were

532 harvested or released into nocodazole-free medium for $12 \mathrm{~h}$ (S-phase) prior to

533 harvesting. (D) FANCD2 was immunoprecipated from M-phase and S-phase

534 synchronized cells using an anti-FANCD2 antibody, and visualized using silver staining

535 (D) or by immunoblotting (E). (F) A schematic of the FANCD2 protein indicating

536 phosphorylation sites identified by LC-MS/MS. (G) HeLa cells were synchronized in M-

537 phase by nocodazole block. Samples were harvested and analyzed by immunoblotting

538 using an anti-FANCD2 antibody and an anti-FANCD2 pS592 phospho-specific

539 antibody.

541 Figure 4. Mutation of S592 disrupts FANCD2 monoubiquitination during S-phase and

542 following exposure to DNA damaging agents

543 (A) Shown is a partial model of the human FANCD2 protein, modeled on the mouse

544 Fancd2 structure (PDB \#3S4W), illustrating the site of monoubiquitination K561 in red

545 and S592 in blue. (B) Site-directed mutagenesis was used to generate phospho-dead

546 (S592A) and phospho-mimetic (S592D) FANCD2 S592 variants. (C) FA-D2 cells stably

547 expressing empty vector or V5-tagged FANCD2-WT, FANCD2-S592A, or FANCD2-

548 S592D were synchronized at the G1/S boundary by double-thymidine block. Cells 
549 were released into thymidine-free medium and whole cell lysates were analyzed by

550 immunoblotting at the indicated times post-release.

552 Figure S3. Mutation on S592 affects cell cycle progression / Cells lacking FANCD2

553 exhibit increased mitotic arrest in unstressed conditions

554 (A) Polyclonal populations of FA-D2 (FANCD2 $2^{-/}$) patient cells expressing empty vector or V5-tagged FANCD2-WT, FANCD2-S592A, or FANCD2-S592D were incubated in

556 the absence (-) or presence (+) of $200 \mathrm{nM}$ mitomycin C (MMC) for $24 \mathrm{~h}$ and whole-cell

557 lysates were analyzed by immunoblotting. (B) Wild-type HeLa and HeLa FANCD2 ${ }^{-/-}$

558 cells generated by CRISPR-Cas9 gene editing were incubated in the absence or

559 presence of $100 \mathrm{nM}$ MMC for $24 \mathrm{~h}$. Cells were fixed and co-immunofluoresence

560 microscopy was performed for FANCD2 (green) and H3 pS10 (red). (C) The same cells

561 were treated with $100 \mathrm{nM} \mathrm{MMC}$ or $1 \mathrm{mM}$ acetaldehyde for $24 \mathrm{~h}$ and whole-cell lysates

562 analyzed by immunoblotting. (D) Cells were incubated in the absence or presence of

$563100 \mathrm{nM}$ MMC or $0.2 \mu \mathrm{M} \mathrm{APH}$ for $24 \mathrm{~h}$. Cells were fixed, stained with propidium iodide

564 and analyzed by flow cytometry. Cell cycle stage analysis was performed using the

565 FlowJo V10.2 software. (E) FA-D2 cells stably expressing empty vector or V5-tagged

566 FANCD2-WT, FANCD2-S592A, or FANCD2-S592D were synchronized at the G1/S

567 boundary by double-thymidine block ( $2 x d T)$, and then released into thymidine-free

568 medium. At the indicated time points, cells were fixed, stained with propidium iodide 
569 and analyzed by flow cytometry. Cell cycle stage analysis was performed using the

570 FlowJo V10.2 software.

572 Figure 5. Mutation of FANCD2 S592 leads to decreased proliferation under conditions

573 of replicative stress and increased mitotic defects

574 (A) FA-D2 cells stably expressing empty vector or V5-tagged FANCD2-WT, FANCD2-

575 S592A, or FANCD2-S592D were incubated in the absence (NT) or presence of $0.4 \mu \mathrm{M}$

576 aphidicolin (+APH) or 20 nM mitomycin C (+MMC). Cellular proliferation was

577 monitored by measuring electrical impedance every 15 minutes over a $120 \mathrm{~h}$ period

578 using the xCELLigence real time cell analysis system. (B) FA-D2 cells stably expressing

579 empty vector or V5-tagged FANCD2-WT, FANCD2-K561R, FANCD2-S592A, or

580 FANCD2-S592D were incubated in the absence of any DNA damaging agents and

581 mitotic aberrations including micronuclei, nucleoplasmic bridges, and multinucleated

582 (>2) cells were scored. At least 400 cells per group were scored and the combined

583 results from two independent experiments are shown. ${ }^{\star \star}, P<0.05 ; * \star \star, P<0.001$.

585 Figure S5. Mutation of FANCD2 S592 leads to decreased proliferation under

587 (A) FA-D2 cells stably expressing empty vector or V5-tagged FANCD2-WT, FANCD2-

588 S592A, or FANCD2-S592D were incubated in the absence (NT) or presence of $0.4 \mu \mathrm{M}$ 
589 aphidicolin (+APH) or $20 \mathrm{nM}$ mitomycin $\mathrm{C}(+\mathrm{MMC})$. Cellular proliferation was

590 monitored by measuring electrical impedance every 15 minutes over a $120 \mathrm{~h}$ period

591 using the xCELLigence real time cell analysis system. Student's t-test was used to

592 compare electrical impedance measurements between populations at $30 \mathrm{~h}, 60 \mathrm{~h}, 90 \mathrm{~h}$

593 and $120 \mathrm{~h}$. (B) The same cells were incubated in the absence or presence of $2 \mu \mathrm{M}$

594 RO3306 and cellular proliferation was monitored by measuring electrical impedance

595 every 15 minutes over a $140 \mathrm{~h}$ period using the xCELLigence real time cell analysis

596 system. (C) Student's t-test was used to compare electrical impedance measurements

597 between populations at 30 h, 60 h, 90 h, 120 h, and $140 \mathrm{~h}$. 
600

601

602

603

604

605

606

607

608

609

610

611

612

613

614

615

616

617

618

619

\section{References}

1. FARF I. Fanconi Anemia: Guidelines for Diagnosis and Management. Fourth ed. Laura Hays P, editor. Eugene, OR: Fanconi Anemia Research Fund, Inc; 2014. 429

p.

2. Kottemann MC, Smogorzewska A. Fanconi anaemia and the repair of Watson and Crick DNA crosslinks. Nature. 2013;493(7432):356-63. Epub 2013/01/18. doi:

10.1038/nature11863. PubMed PMID: 23325218; PubMed Central PMCID:

PMC3700363.

3. Garcia-Higuera I, Taniguchi T, Ganesan S, Meyn MS, Timmers C, Hejna J, et al.

Interaction of the Fanconi anemia proteins and BRCA1 in a common pathway. Mol

Cell. 2001;7(2):249-62. PubMed PMID: 11239454.

4. Taniguchi T, Garcia-Higuera I, Andreassen PR, Gregory RC, Grompe M, D'Andrea AD. S-phase-specific interaction of the Fanconi anemia protein, FANCD2, with BRCA1 and RAD51. Blood. 2002;100(7):2414-20. PubMed PMID: 12239151.

5. Alcón P, Shakeel S, Chen ZA, Rappsilber J, Patel KJ, Passmore LA. FANCD2FANCl is a clamp stabilized on DNA by monoubiquitination of FANCD2 during DNA repair. Nat Struct Mol Biol. 2020;27(3):240-8. Epub 2020/02/19. doi: 10.1038/s41594-020-0380-1. PubMed PMID: 32066963; PubMed Central PMCID: PMCPMC7067600. 
620

621

622

623

624

625

626

627

628

629

630

631

632

633

634

635

636

637

638

6. Wang R, Wang S, Dhar A, Peralta C, Pavletich NP. DNA clamp function of the monoubiquitinated Fanconi anaemia ID complex. Nature. 2020;580(7802):278-82.

Epub 2020/04/10. doi: 10.1038/s41586-020-2110-6. PubMed PMID: 32269332;

PubMed Central PMCID: PMCPMC7398534.

7. Tan W, van Twest S, Leis A, Bythell-Douglas R, Murphy VJ, Sharp M, et al.

Monoubiquitination by the human Fanconi anemia core complex clamps

FANCI:FANCD2 on DNA in filamentous arrays. eLife. 2020;9. Epub 2020/03/14.

doi: 10.7554/eLife.54128. PubMed PMID: 32167469; PubMed Central PMCID:

PMCPMC7156235.

8. Howlett NG, Taniguchi T, Durkin SG, D'Andrea AD, Glover TW. The Fanconi anemia pathway is required for the DNA replication stress response and for the regulation of common fragile site stability. Hum Mol Genet. 2005;14(5):693-701. PubMed PMID: 15661754.

9. Vinciguerra P, Godinho SA, Parmar K, Pellman D, D'Andrea AD. Cytokinesis failure occurs in Fanconi anemia pathway-deficient murine and human bone marrow hematopoietic cells. J Clin Invest. 2010;120(11):3834-42. doi: 10.1172/JCI43391. PubMed PMID: 20921626 ; PubMed Central PMCID: PMCPMC2964984.

10. Madireddy A, Kosiyatrakul ST, Boisvert RA, Herrera-Moyano E, Garcia-Rubio ML, Gerhardt J, et al. FANCD2 Facilitates Replication through Common Fragile Sites. 
Mol Cell. 2016;64(2):388-404. doi: 10.1016/j.molcel.2016.09.017. PubMed PMID: 27768874.

641

11. Schlacher K, Wu H, Jasin M. A distinct replication fork protection pathway connects Fanconi anemia tumor suppressors to RAD51-BRCA1/2. Cancer Cell. 2012;22(1):106-16. doi: 10.1016/j.ccr.2012.05.015. PubMed PMID: 22789542; PubMed Central PMCID: PMC3954744.

12. Chan $\mathrm{KL}$, Hickson ID. New insights into the formation and resolution of ultra-fine anaphase bridges. Semin Cell Dev Biol. 2011;22(8):906-12. Epub 2011/07/26. doi: 10.1016/j.semcdb.2011.07.001. PubMed PMID: 21782962.

13. Chan KL, Palmai-Pallag T, Ying S, Hickson ID. Replication stress induces sisterchromatid bridging at fragile site loci in mitosis. Nat Cell Biol. 2009;11(6):753-60. Epub 2009/05/26. doi: ncb1882 [pii] 10.1038/ncb1882. PubMed PMID: 19465922.

14. Chen YH, Jones MJ, Yin Y, Crist SB, Colnaghi L, Sims RJ, 3rd, et al. ATR-mediated phosphorylation of $\mathrm{FANCl}$ regulates dormant origin firing in response to replication stress. Mol Cell. 2015;58(2):323-38. doi: 10.1016/j.molcel.2015.02.031. PubMed PMID: 25843623; PubMed Central PMCID: PMC4408929.

15. Cheung RS, Castella M, Abeyta A, Gafken PR, Tucker N, Taniguchi T. Ubiquitination-Linked Phosphorylation of the FANCI S/TQ Cluster Contributes to Activation of the Fanconi Anemia I/D2 Complex. Cell Rep. 2017;19(12):2432-40. 
658

659

660

661

662

663

664

665

666

667

668

669

670

671

672

673

674

675

676

doi: 10.1016/j.celrep.2017.05.081. PubMed PMID: 28636932; PubMed Central

PMCID: PMCPMC5538132.

16. Ho GP, Margossian S, Taniguchi T, D'Andrea AD. Phosphorylation of FANCD2 on two novel sites is required for mitomycin C resistance. Mol Cell Biol. 2006;26(18):7005-15.

17. Taniguchi T, Garcia-Higuera I, Xu B, Andreassen PR, Gregory RC, Kim ST, et al. Convergence of the fanconi anemia and ataxia telangiectasia signaling pathways. Cell. 2002;109(4):459-72. PubMed PMID: 12086603.

18. Wohlbold L, Fisher RP. Behind the wheel and under the hood: functions of cyclindependent kinases in response to DNA damage. DNA Repair (Amst). 2009;8(9):1018-24. Epub 2009/05/26. doi: 10.1016/j.dnarep.2009.04.009. PubMed PMID: 19464967; PubMed Central PMCID: PMCPMC2725215.

19. Esashi F, Christ N, Gannon J, Liu Y, Hunt T, Jasin M, et al. CDK-dependent phosphorylation of BRCA2 as a regulatory mechanism for recombinational repair. Nature. 2005;434(7033):598-604. Epub 2005/04/01. doi: nature03404 [pii] 10.1038/nature03404. PubMed PMID: 15800615.

20. Tomimatsu N, Mukherjee B, Catherine Hardebeck M, Ilcheva M, Vanessa Camacho C, Louise Harris J, et al. Phosphorylation of EXO1 by CDKs 1 and 2 regulates DNA end resection and repair pathway choice. Nat Commun. 
2014;5:3561. Epub 2014/04/08. doi: 10.1038/ncomms4561. PubMed PMID:

24705021; PubMed Central PMCID: PMCPMC4041212.

21. Garcia-Higuera I, Kuang Y, Denham J, D'Andrea AD. The Fanconi Anemia Proteins, FANCA and FANCG, stabilize each other and promote the nuclear accumulation of the FA complex. Blood. 2000;96:3224-30.

22. Huertas P, Jackson SP. Human CtIP mediates cell cycle control of DNA end resection and double strand break repair. J Biol Chem. 2009;284(14):9558-65. Epub 2009/02/10. doi: M808906200 [pii] 10.1074/jbc.M808906200. PubMed PMID: 19202191; PubMed Central PMCID: PMC2666608.

23. Yu X, Chini CC, He M, Mer G, Chen J. The BRCT domain is a phospho-protein binding domain. Science. 2003;302(5645):639-42. Epub 2003/10/25. doi: 10.1126/science.1088753302/5645/639 [pii]. PubMed PMID: 14576433.

24. van Twest S, Murphy VJ, Hodson C, Tan W, Swuec P, O'Rourke JJ, et al. Mechanism of Ubiquitination and Deubiquitination in the Fanconi Anemia Pathway. Mol Cell. 2017;65(2):247-59. Epub 2016/12/18. doi: 10.1016/j.molcel.2016.11.005. PubMed PMID: 27986371.

25. Liang CC, Li Z, Lopez-Martinez D, Nicholson WV, Venien-Bryan C, Cohn MA. The FANCD2-FANCl complex is recruited to DNA interstrand crosslinks before monoubiquitination of FANCD2. Nat Commun. 2016;7:12124. Epub 2016/07/14. 
doi: 10.1038/ncomms12124. PubMed PMID: 27405460; PubMed Central PMCID: PMCPMC4947157.

26. Ishiai M, Kitao H, Smogorzewska A, Tomida J, Kinomura A, Uchida E, et al. FANCl phosphorylation functions as a molecular switch to turn on the Fanconi anemia pathway. Nat Struct Mol Biol. 2008;15(11):1138-46. Epub 2008/10/22. doi: nsmb.1504 [pii] 10.1038/nsmb.1504. PubMed PMID: 18931676. mechanism for site-specific ubiquitination of FANCD2. Nat Chem Biol. PubMed Central PMCID: PMCPMC7035956. complementation group FANCD2 protein serine 331 phosphorylation is important monoubiquitination to the DNA-damage response. Genes Dev. 2004;18(16):195863. PubMed PMID: 15314022. for fanconi anemia pathway function and BRCA2 interaction. Cancer Res. 2009;69(22):8775-83. Epub 2009/10/29. doi: 10.1158/0008-5472.can-09-2312. PubMed PMID: 19861535; PubMed Central PMCID: PMCPMC5912675. 
Suppresses the Fanconi Anemia Pathway in the Absence of DNA Damage. Cell reports. 2019;27(10):2990-3005.e5. Epub 2019/06/06. doi:

10.1016/j.celrep.2019.05.003. PubMed PMID: 31167143; PubMed Central PMCID: PMCPMC6581795.

31. Wang H, Shi LZ, Wong CC, Han X, Hwang PY, Truong LN, et al. The interaction of CtIP and Nbs1 connects CDK and ATM to regulate HR-mediated double-strand break repair. PLoS Genet. 2013;9(2):e1003277. Epub 2013/03/08. doi: 10.1371/journal.pgen.1003277. PubMed PMID: 23468639; PubMed Central PMCID: PMCPMC3585124.

32. Nakanishi K, Yang YG, Pierce AJ, Taniguchi T, Digweed M, D'Andrea AD, et al. Human Fanconi anemia monoubiquitination pathway promotes homologous DNA repair. Proc Natl Acad Sci U S A. 2005;102(4):1110-5. PubMed PMID: 15650050.

33. Garcia-Rubio ML, Perez-Calero C, Barroso SI, Tumini E, Herrera-Moyano E, Rosado IV, et al. The Fanconi Anemia Pathway Protects Genome Integrity from Rloops. PLoS Genet. 2015;11(11):e1005674. Epub 2015/11/20. doi: 10.1371/journal.pgen.1005674. PubMed PMID: 26584049; PubMed Central PMCID: PMCPmc4652862.

34. Schwab RA, Nieminuszczy J, Shah F, Langton J, Lopez Martinez D, Liang CC, et al. The Fanconi Anemia Pathway Maintains Genome Stability by Coordinating Replication and Transcription. Mol Cell. 2015;60(3):351-61. Epub 2015/11/26. doi: 
10.1016/j.molcel.2015.09.012. PubMed PMID: 26593718; PubMed Central

PMCID: PMCPmc4644232.

PMID: 26633632. 
A

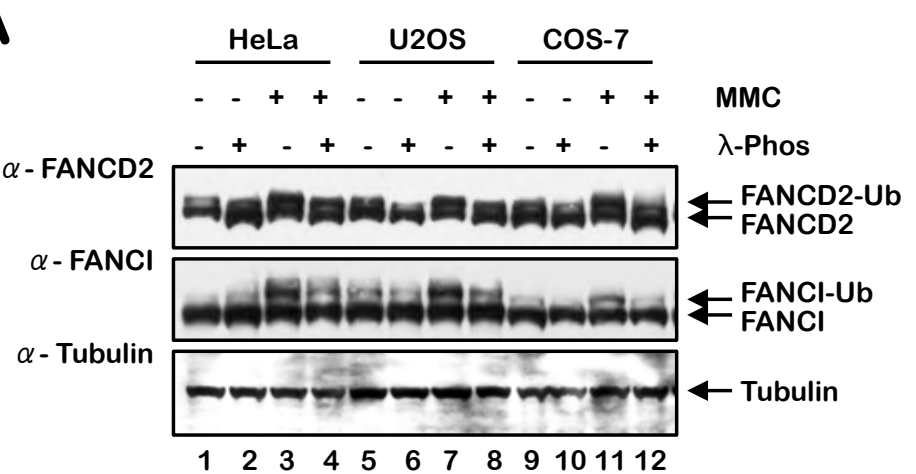

B

\begin{tabular}{cccc}
\multicolumn{2}{c}{ Wash } & Wash & Wash \\
dT & $\downarrow$ Release $\downarrow$ & dT & $\downarrow$ Release \\
$18 \mathrm{~h}$ & $10 \mathrm{~h}$ & $18 \mathrm{~h}$
\end{tabular}

HeLa

2x Thymidine Block (dT)
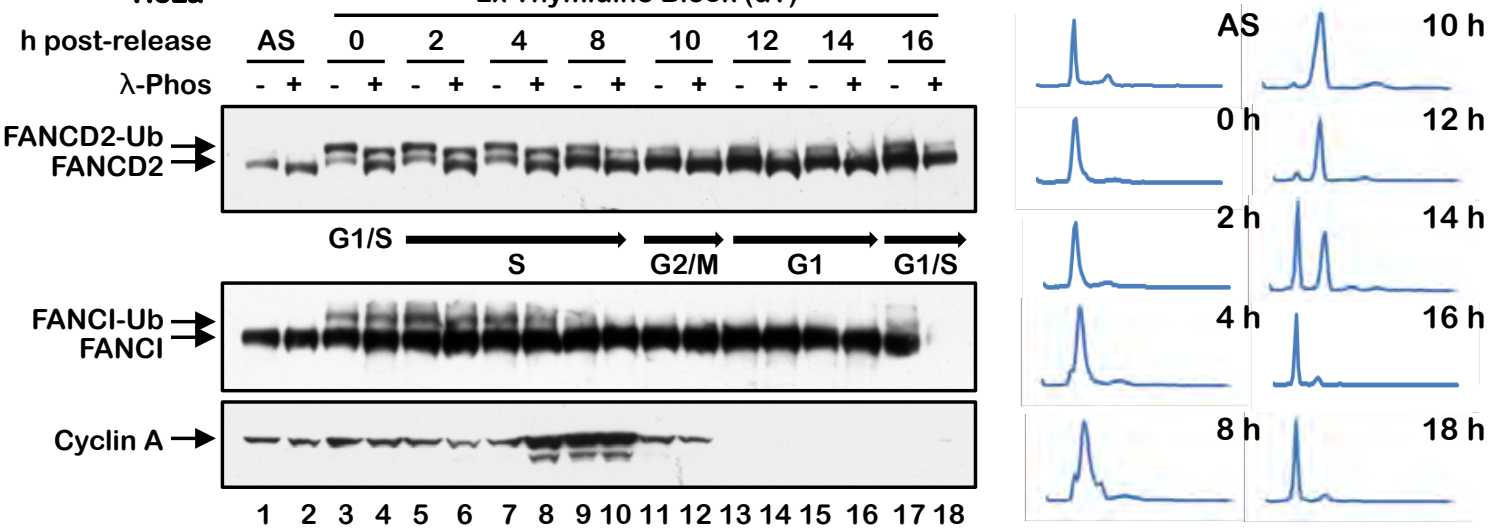

C

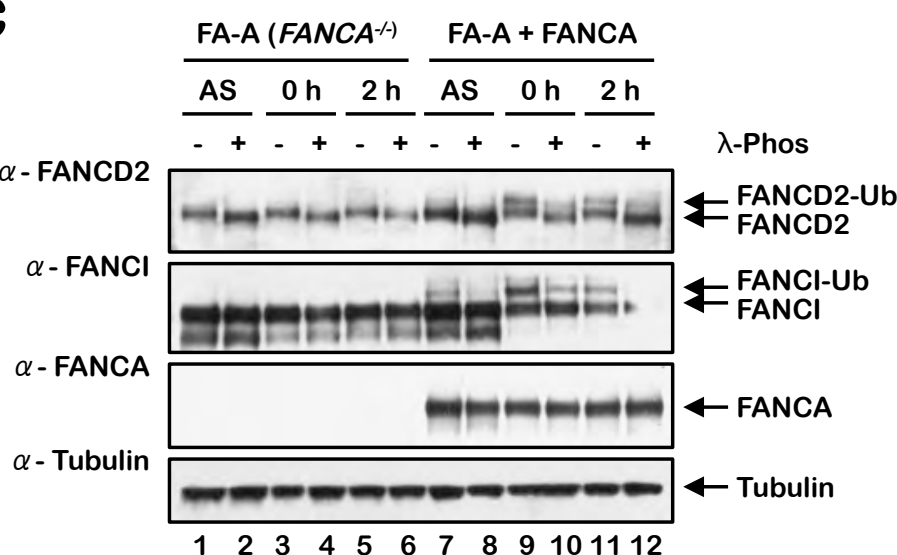


bioRxiv preprint doi: https://doi.org/10.1101/2020.09.29.318055; this version posted September 29, 2020. The copyright holder for this preprint (which was not certified by peer review) is the author/funder, who has granted bioRxiv a license to display the preprint in perpetuity. It is made available under aCC-BY 4.0 International license.
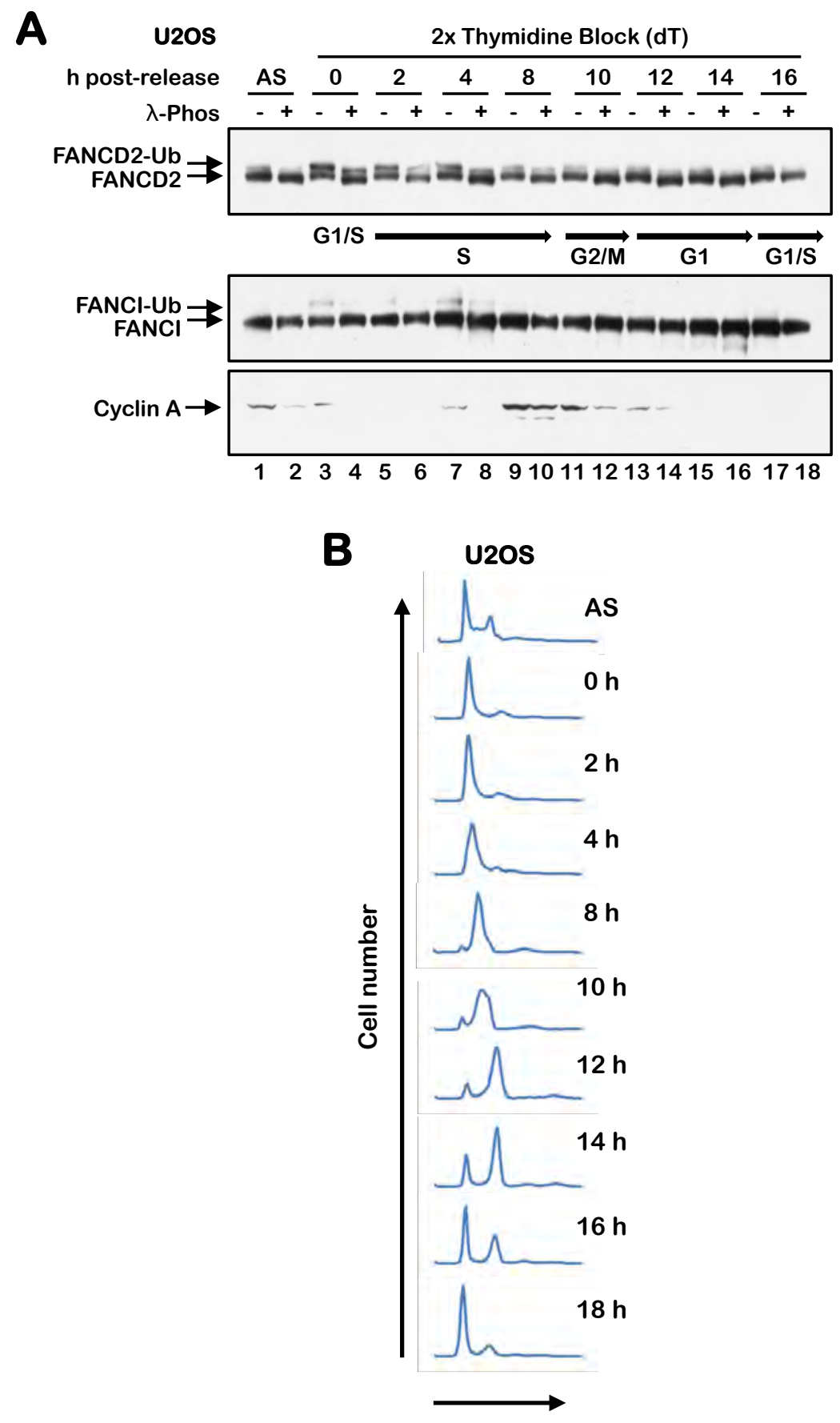

Propidium iodide 
bioRxiv preprint doi: $h$ ttps://doi org/10.1101/2020.09 29.318055; this version posted September 29,2020 . The copyright holder for this preprint (which was not certified by peer review) is the author/funder, who has granted bioRxiv a license to display the preprint in perpetuity. It is made available under ACC-BY 4.0 International license.
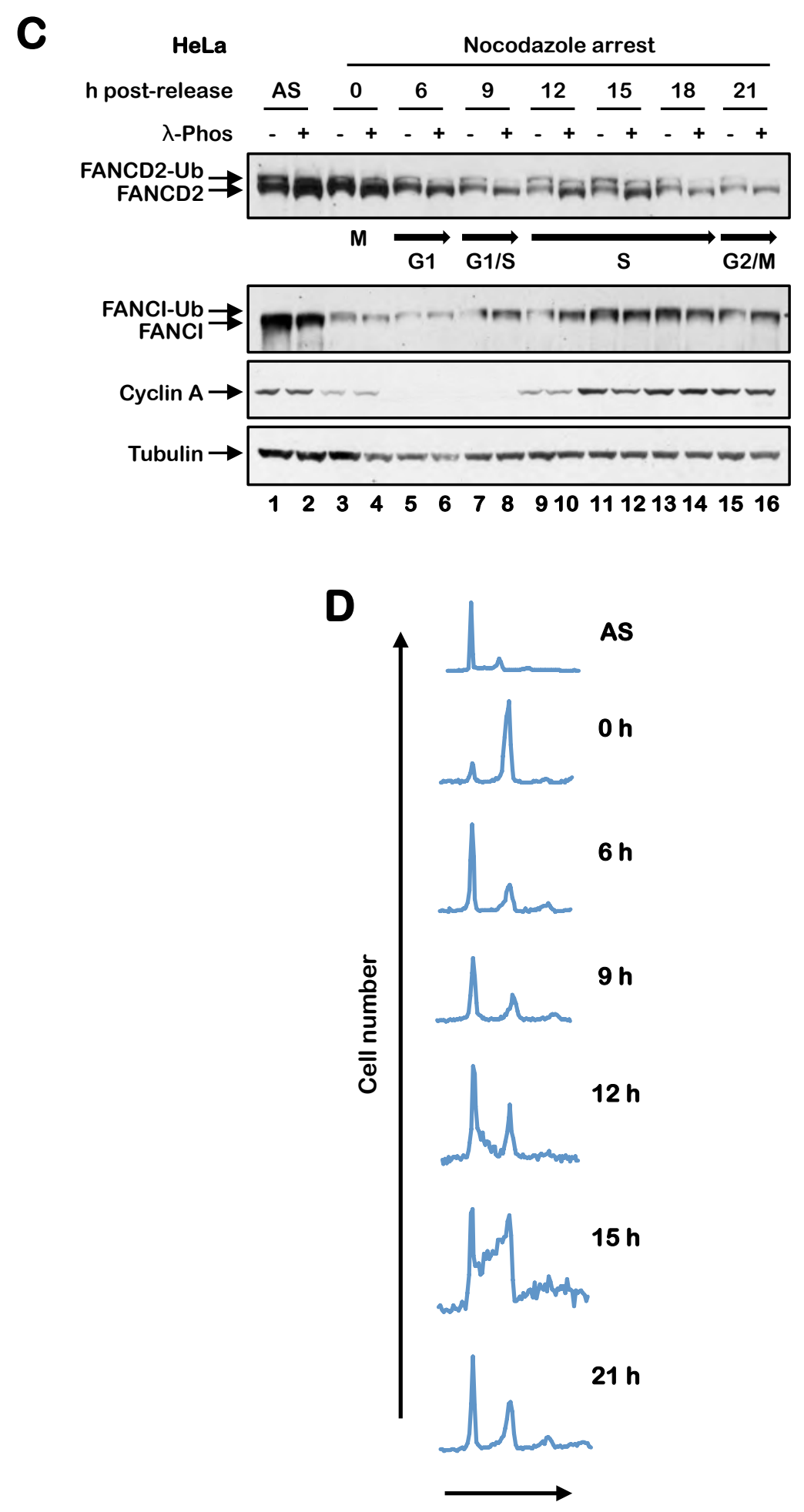

Propidium iodide 
bioRxiv preprint doi: https://doi.org/10.1101/2020.09.29.318055; this version posted September 29, 2020. The copyright holder for this preprint (which was not certified by peer review) is the author/funder, who has granted bioRxiv a license to display the preprint in perpetuity. It is made available under aCC-BY 4.0 International license.

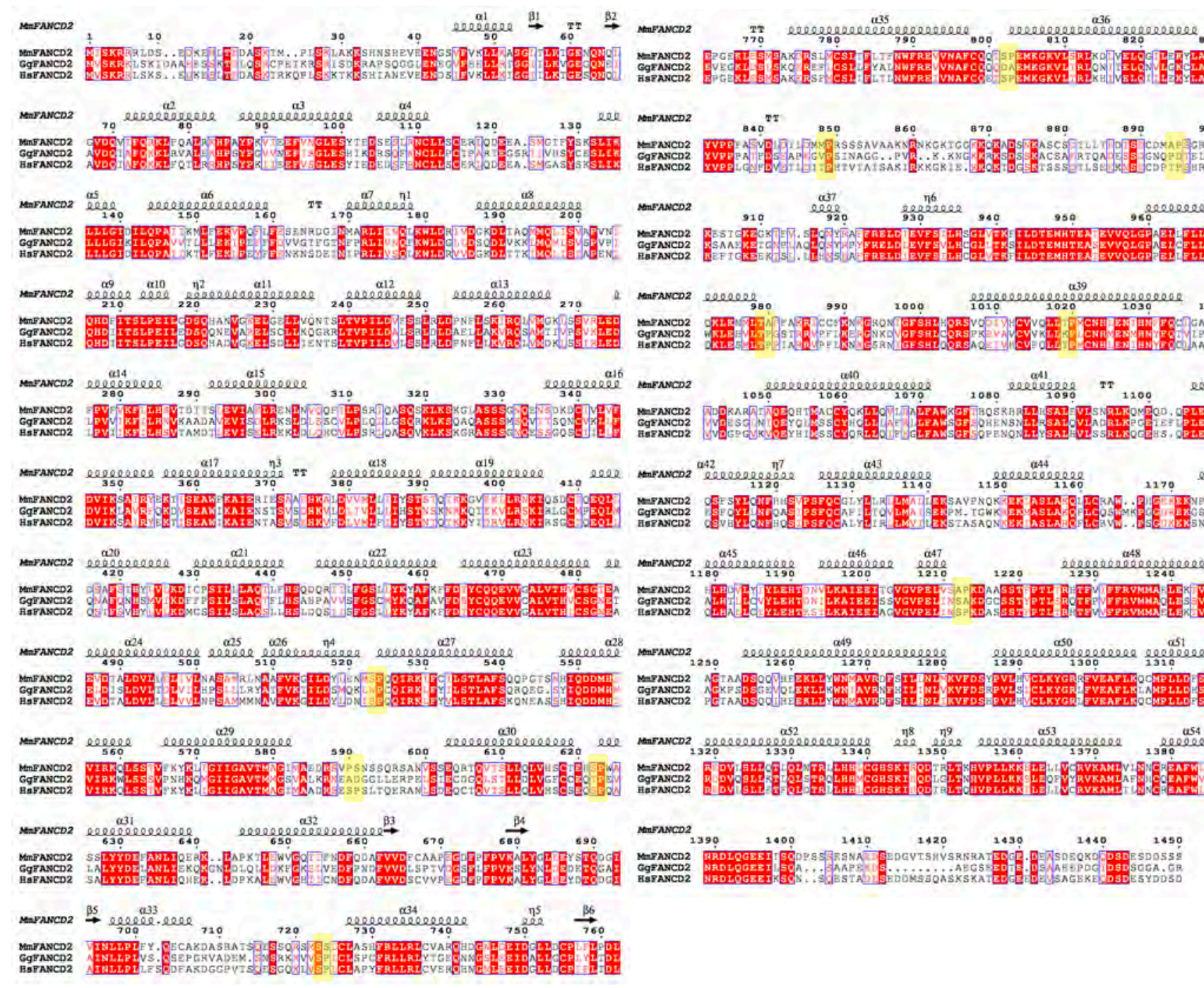


bioRxiv preprint doi: https://doi.org/10.1101/2020.09.29.318055; this version posted September 29, 2020. The copyright holder for this preprint (which was not certified by peer review) is the author/funder, who has granted bioRxiv a license to display the preprint in perpetuity. It is made available under aCC-BY 4.0 International license.

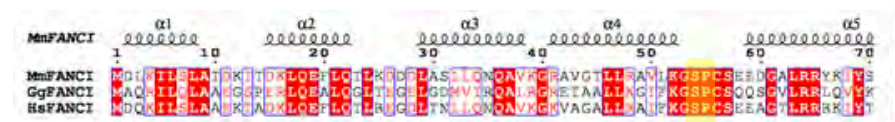

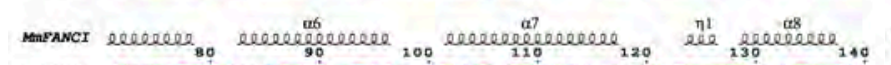

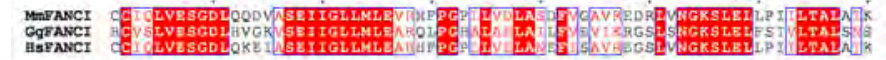

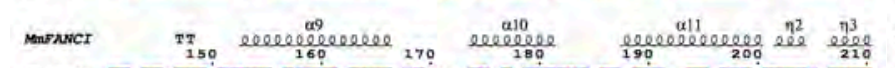

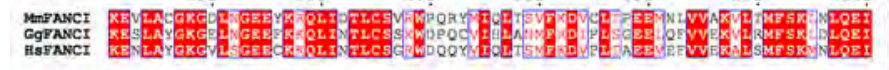

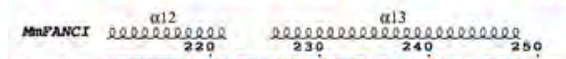
260 perenesereserese

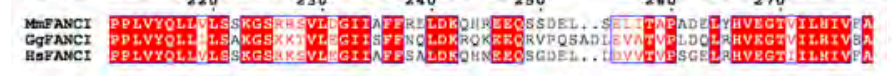

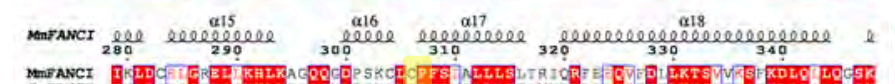

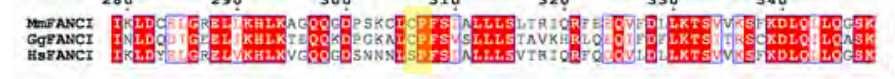

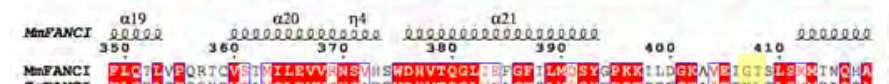

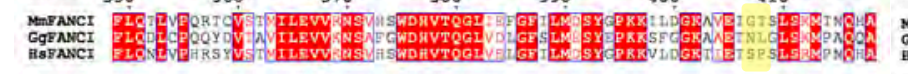

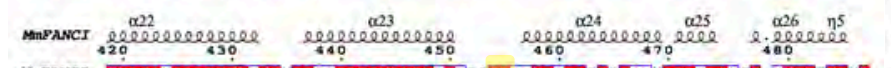

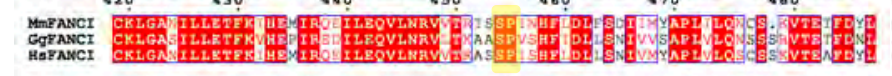

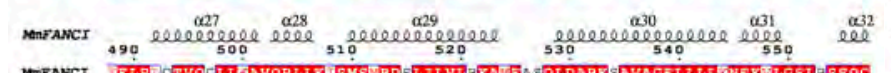

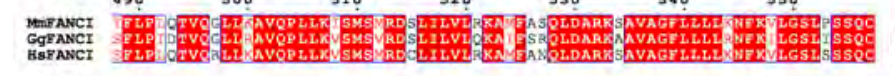

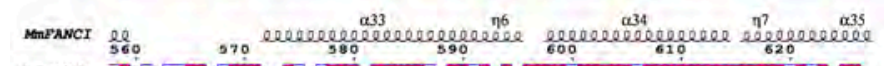

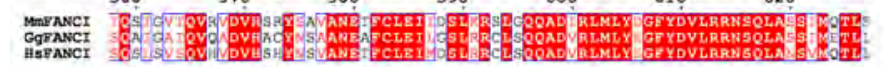

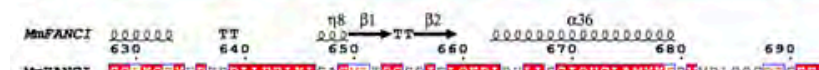

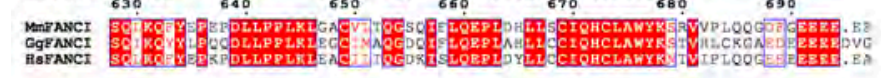

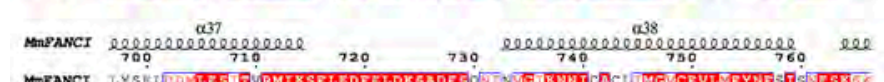

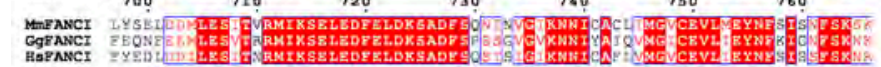

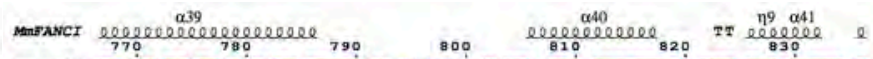

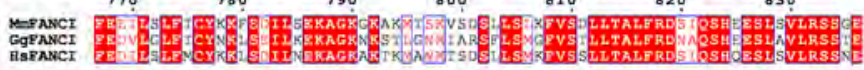

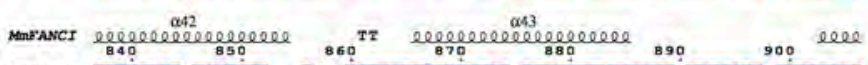

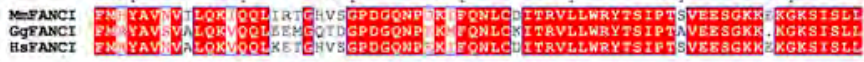

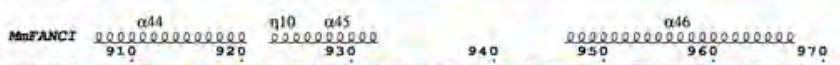

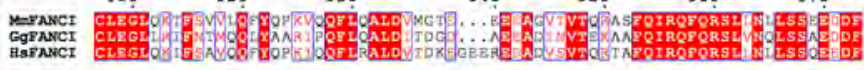

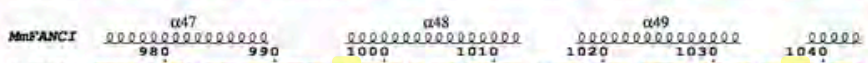

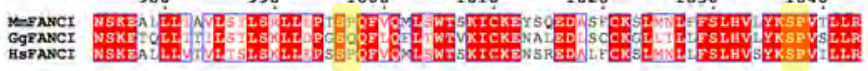

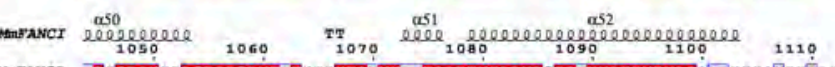

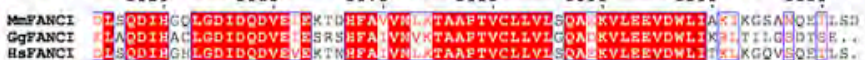
xaovsontas.

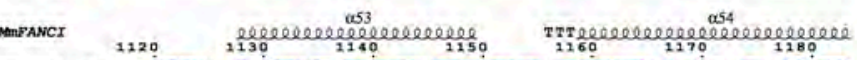

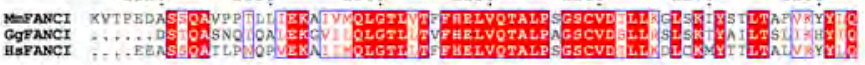

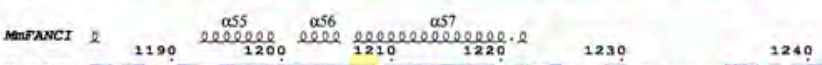

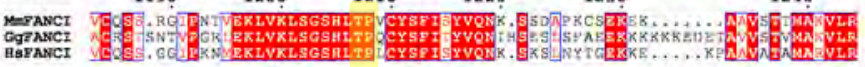

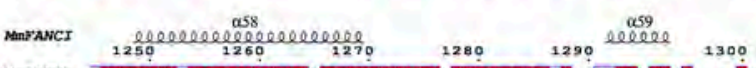

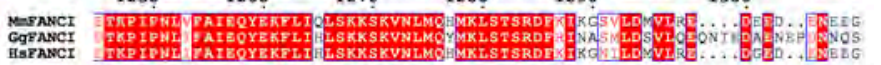
1320

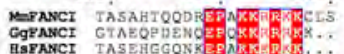


bioRxiv preprint doi: https://doi.org/10.1101/2020.09.29.318055; this version posted September 29, 2020. The copyright holder for this preprint (which was not certified by peer review) is the author/funder, who has granted bioRxiv a license to display the preprint in perpetuity. It is made available under aCC-BY 4.0 International license.

\begin{tabular}{|c|c|c|c|c|c|}
\hline \multirow{3}{*}{$A$} & & Wash & Wash & dT + & Wash \\
\hline & CDKi & $\downarrow$ Release & & CDKi & \\
\hline & $18 \mathrm{~h}$ & $10 \mathrm{~h}$ & & $18 \mathrm{~h}$ & \\
\hline
\end{tabular}
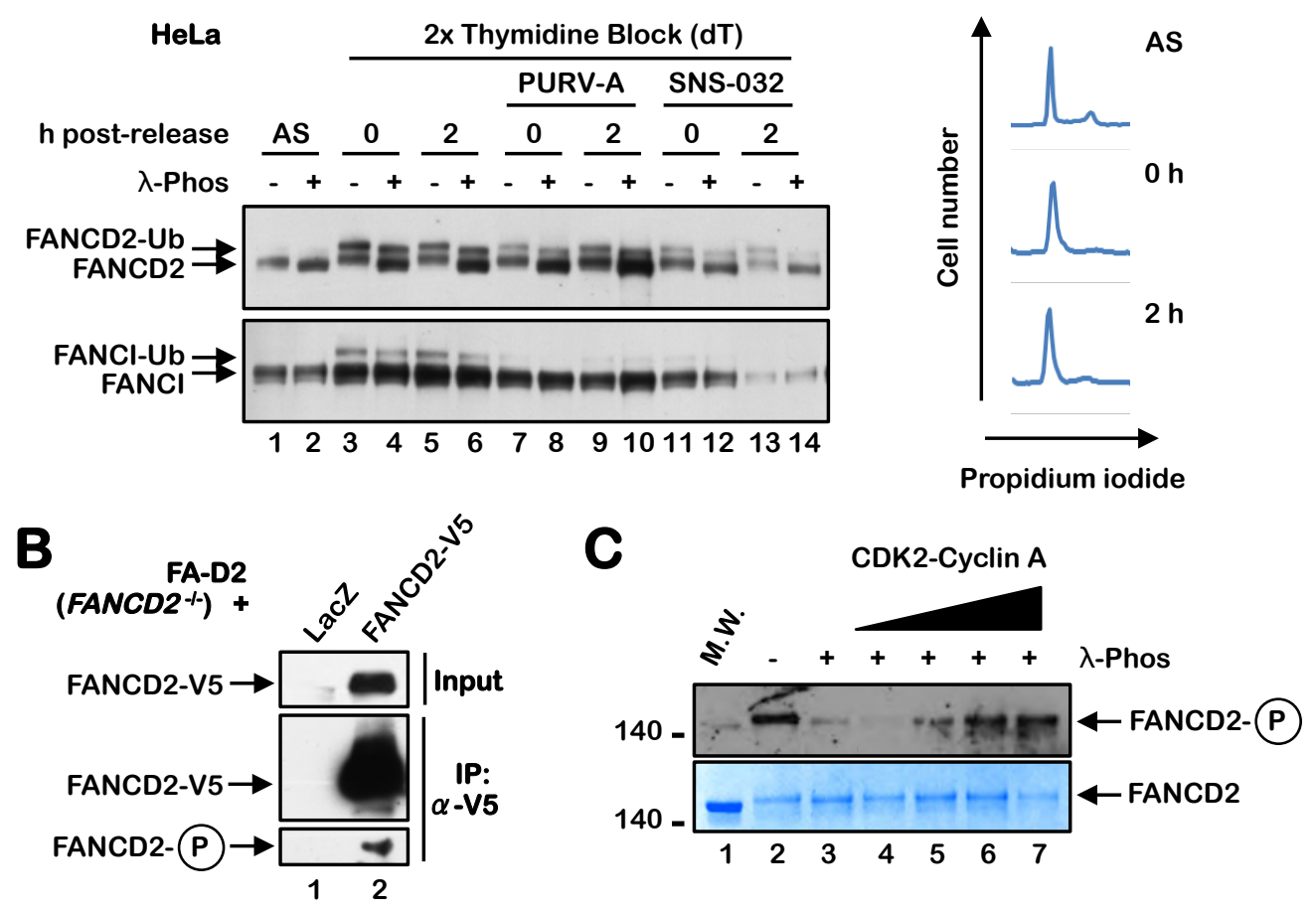
bioRxiv preprint doi: https://doi.org/10.1101/2020.09.29.318055; this version posted September 29, 2020. The copyright holder for this preprint (which was not certified by peer review) is the author/funder, who has granted bioRxiv a license to display the preprint in perpetuity. It is made available under aCC-BY 4.0 International license.
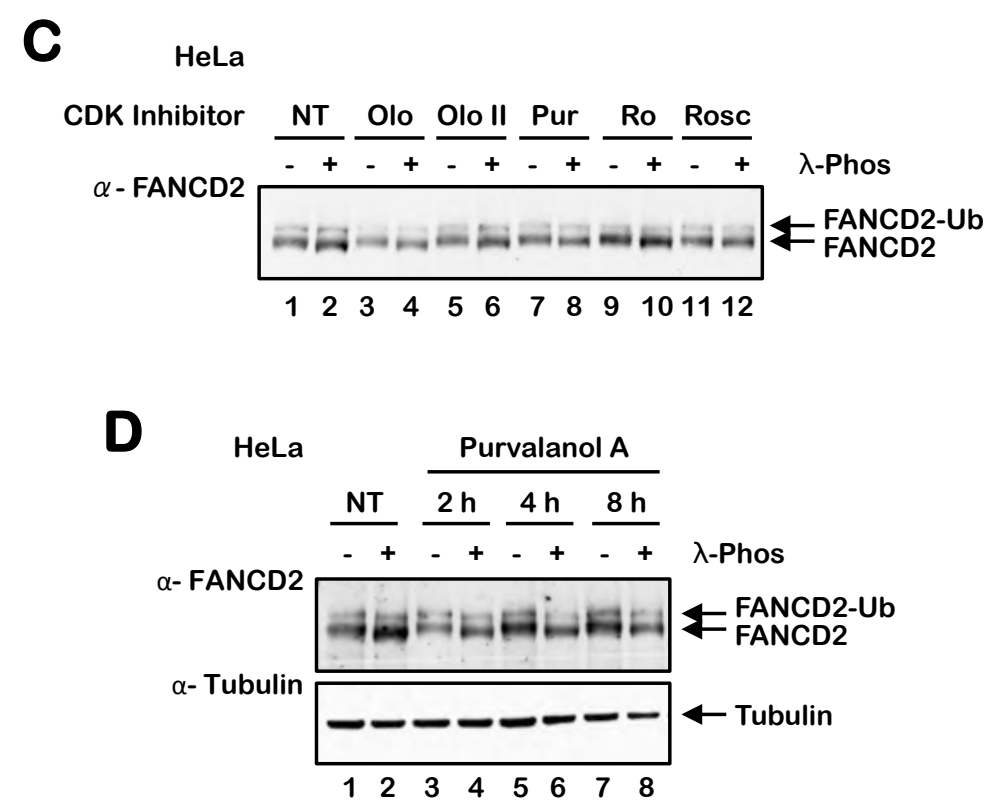


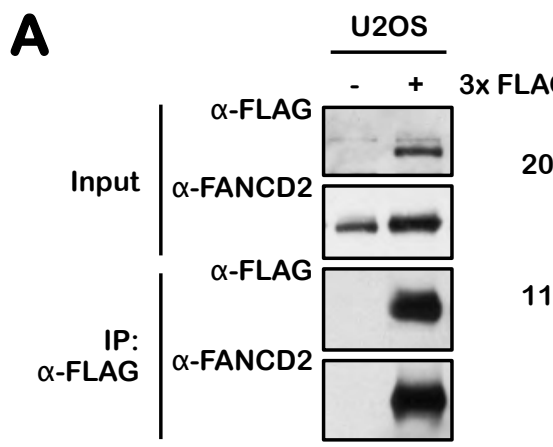

C

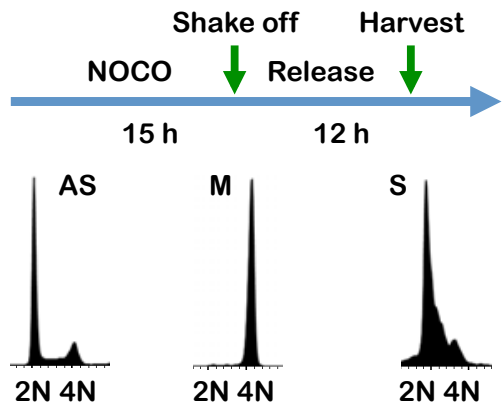

B

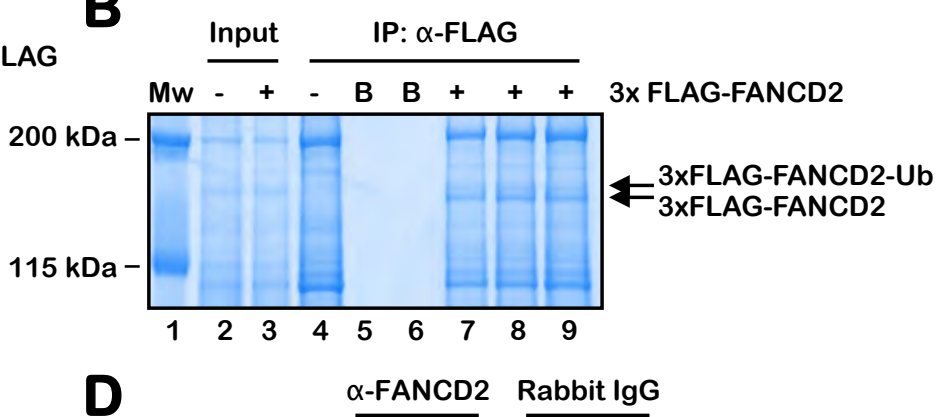

E

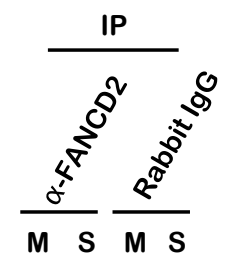

D
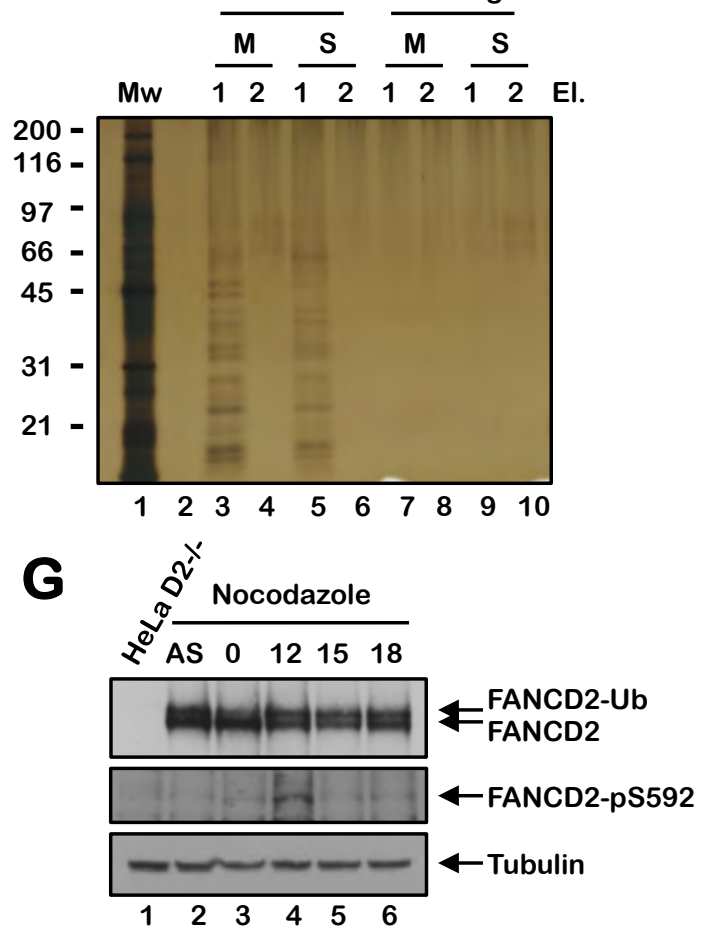

$\mathbf{F}$

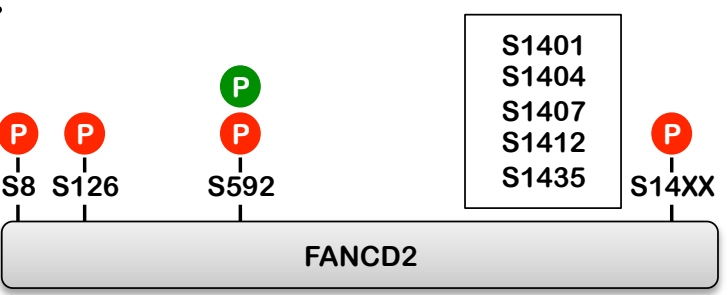


A

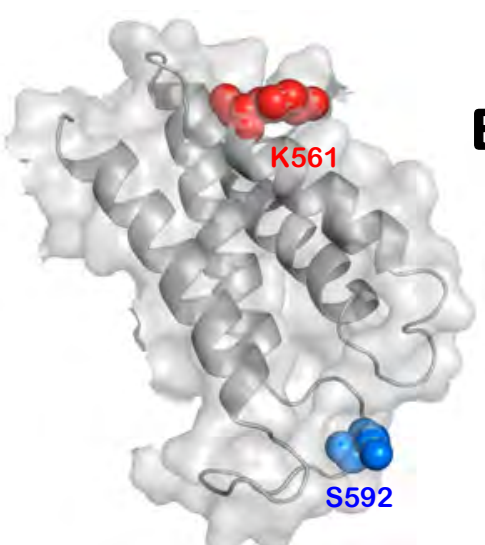

B

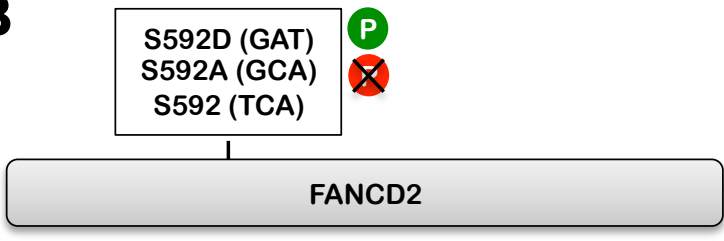

C
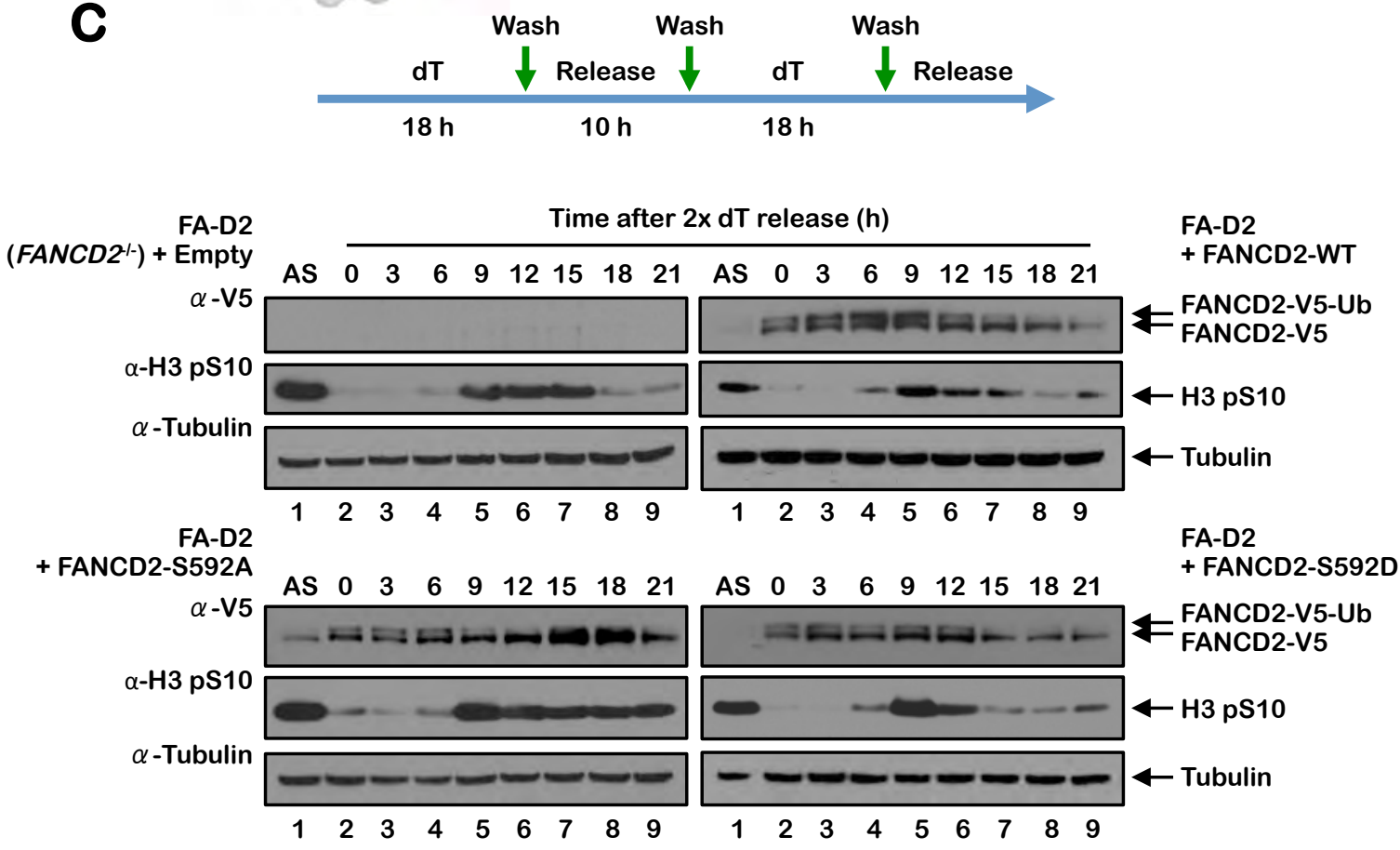


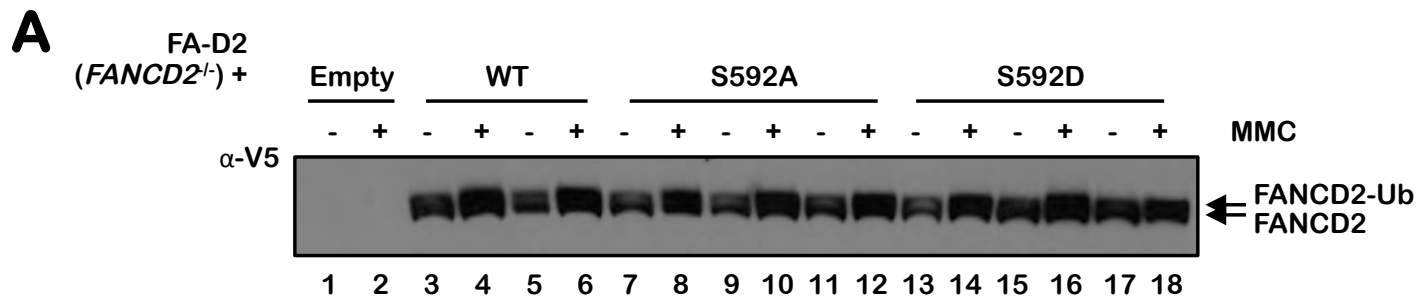

B HeLa

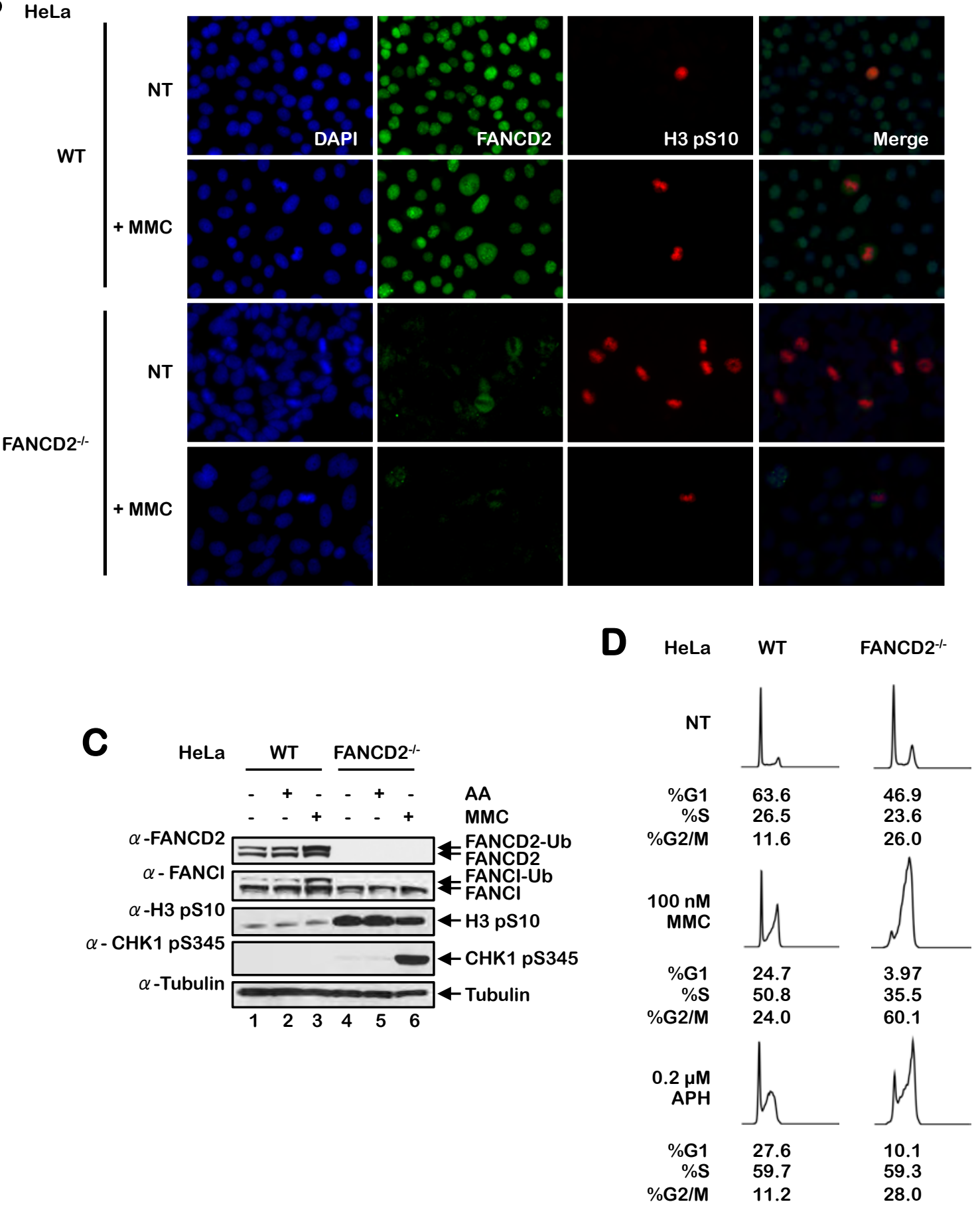


E

Time after $2 x d T$ release $(h)$

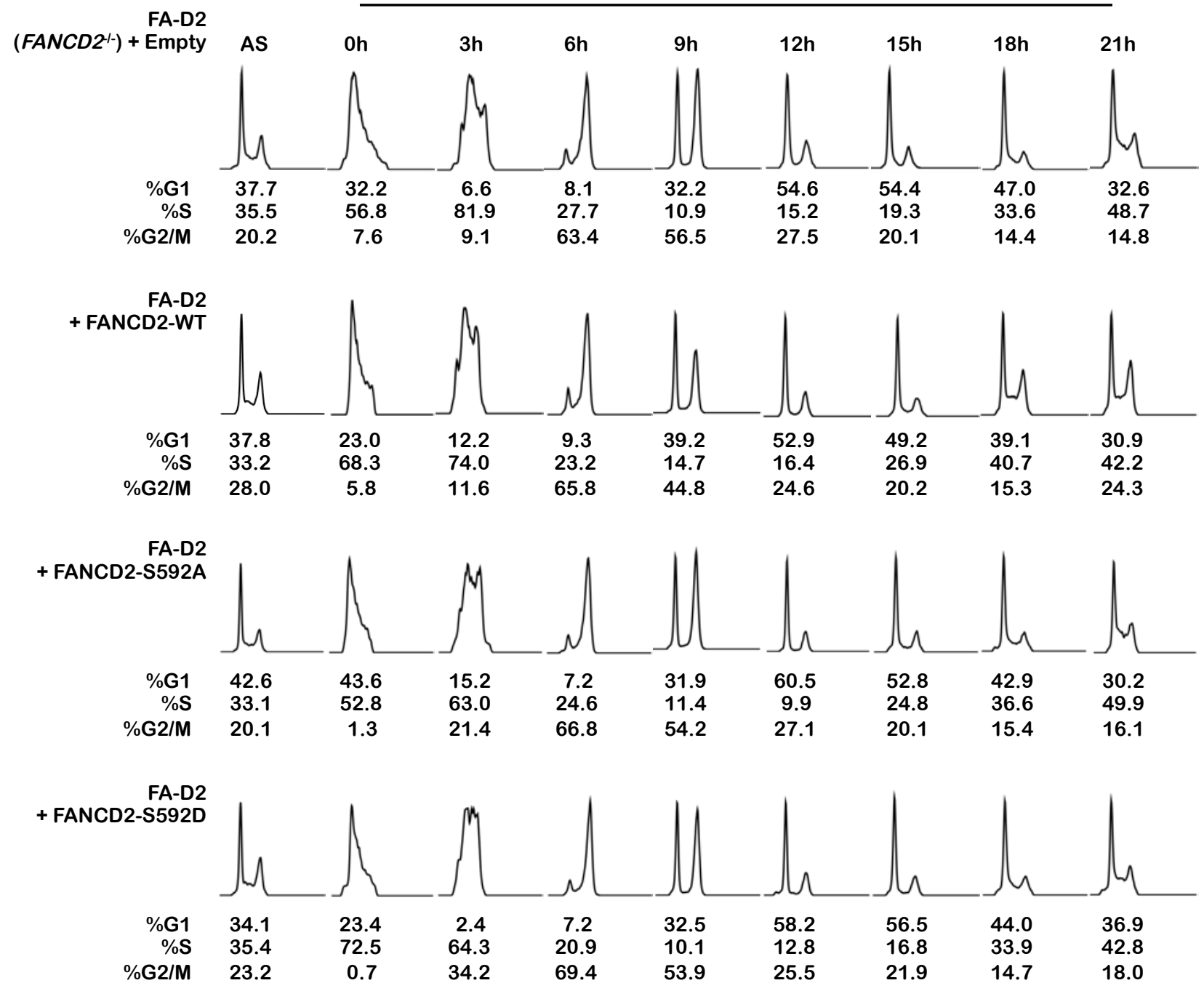



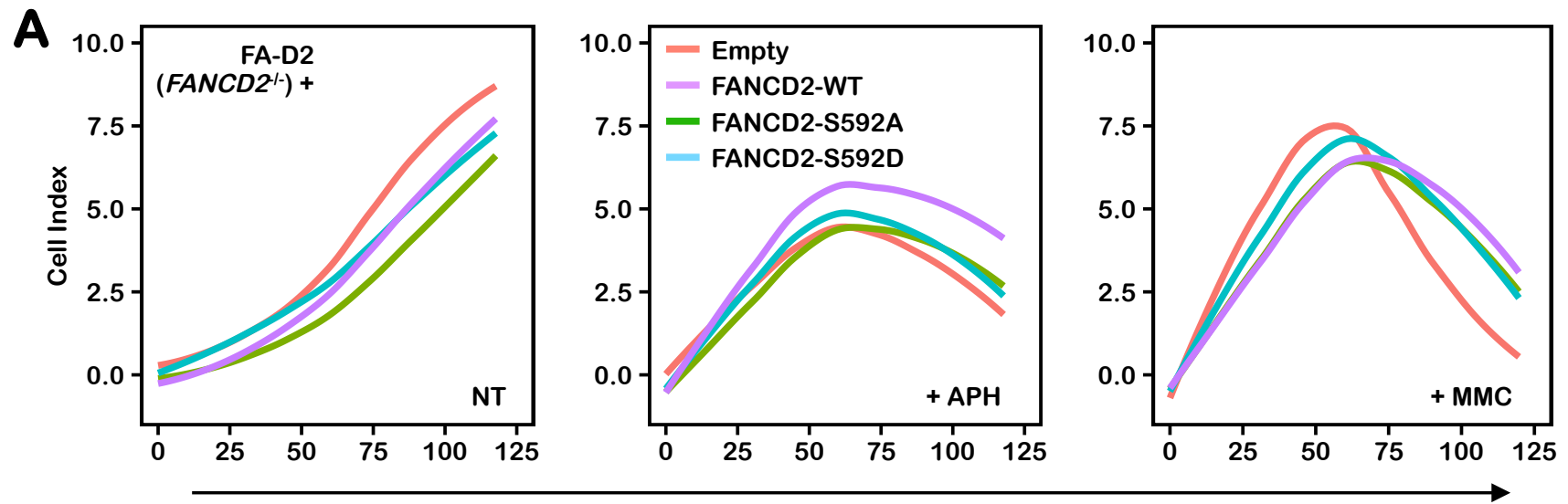

Time (h)

B

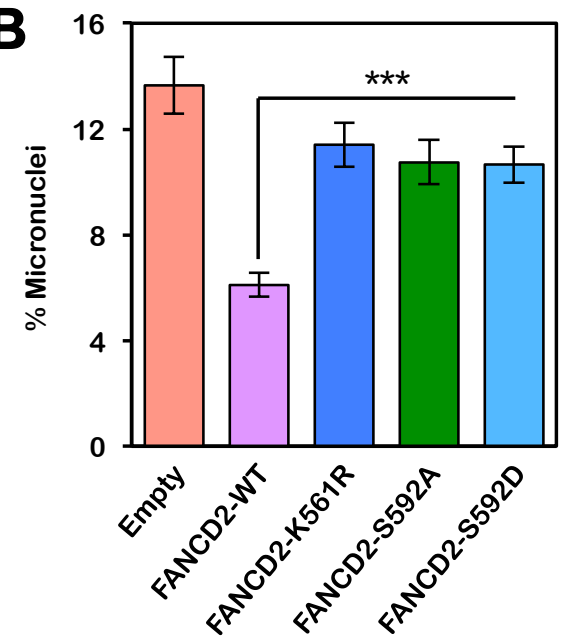

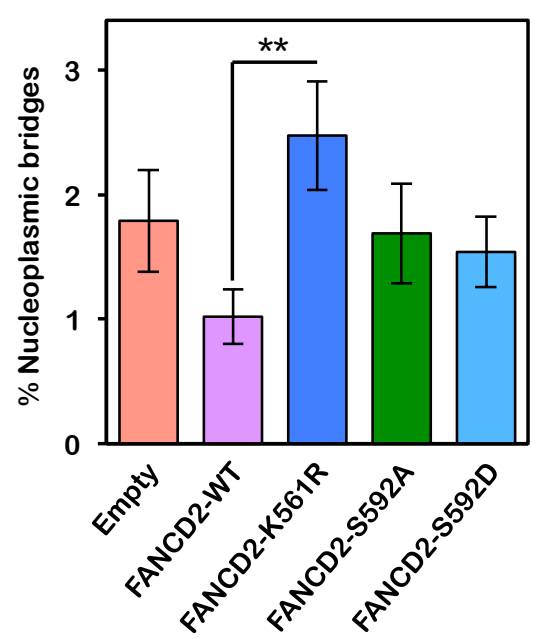

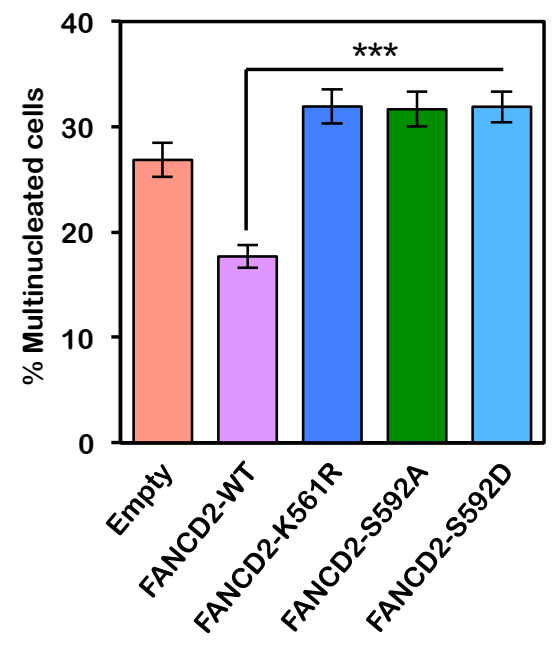

FA-D2

$($ FANCD2-1) +

Cell line 


\begin{tabular}{|c|c|c|c|c|}
\hline NT & $30 \mathrm{~h}$ & $60 \mathrm{~h}$ & $90 \mathrm{~h}$ & $120 \mathrm{~h}$ \\
\hline E-WT & 0.038 & 0.084 & 0.066 & 0.131 \\
\hline E-SA & 0.014 & 0.015 & 0.011 & 0.015 \\
\hline E-SD & 0.913 & 0.292 & 0.061 & 0.053 \\
\hline WT-SA & 0.448 & 0.022 & 0.002 & 0.005 \\
\hline WT-SD & 0.064 & 0.363 & 0.811 & 0.296 \\
\hline SA-SD & 0.249 & 0.035 & 0.070 & 0.228 \\
\hline
\end{tabular}

\begin{tabular}{|c|c|c|c|c|}
\hline $\begin{array}{c}0.4 \mu M \\
\text { APH }\end{array}$ & $30 \mathrm{~h}$ & $60 \mathrm{~h}$ & $90 \mathrm{~h}$ & $120 \mathrm{~h}$ \\
\hline E-WT & 0.359 & 0.377 & 0.088 & 0.015 \\
\hline E-SA & 0.524 & 0.969 & 0.632 & 0.273 \\
\hline E-SD & 0.976 & 0.786 & 0.490 & 0.465 \\
\hline WT-SA & 0.116 & 0.176 & 0.029 & 0.025 \\
\hline WT-SD & 0.045 & 0.053 & 0.034 & 0.019 \\
\hline SA-SD & 0.389 & 0.625 & 0.724 & 0.635 \\
\hline
\end{tabular}

\begin{tabular}{|c|c|c|c|c|}
\hline $\begin{array}{c}20 \mathrm{nM} \\
\text { MMC }\end{array}$ & $30 \mathrm{~h}$ & $60 \mathrm{~h}$ & $90 \mathrm{~h}$ & $118 \mathrm{~h}$ \\
\hline E-WT & 0.034 & 0.072 & 0.010 & 0.0004 \\
\hline E-SA & 0.021 & 0.021 & 0.001 & 0.002 \\
\hline E-SD & 0.009 & 0.173 & 0.003 & 0.006 \\
\hline WT-SA & 0.923 & 0.935 & 0.214 & 0.096 \\
\hline WT-SD & 0.085 & 0.177 & 0.280 & 0.052 \\
\hline SA-SD & 0.052 & 0.096 & 0.743 & 0.463 \\
\hline
\end{tabular}




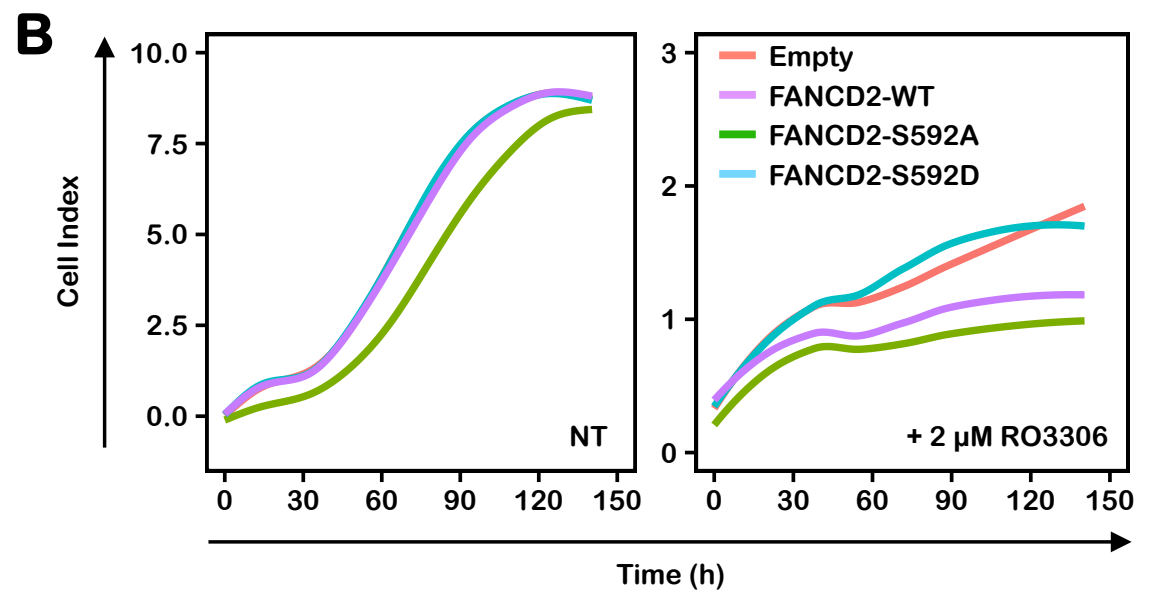

\begin{tabular}{|c|c|c|c|c|c|}
\hline NT & $30 \mathrm{~h}$ & $60 \mathrm{~h}$ & $90 \mathrm{~h}$ & $120 \mathrm{~h}$ & $140 \mathrm{~h}$ \\
\hline E-WT & 0.645 & 0.492 & 0.852 & 0.938 & 0.505 \\
\hline E-SA & 0.265 & 0.059 & 0.027 & 0.135 & 0.152 \\
\hline E-SD & 0.859 & 0.979 & 0.871 & 0.838 & 0.907 \\
\hline WT-SA & 0.286 & 0.111 & 0.059 & 0.114 & 0.077 \\
\hline WT-SD & 0.884 & 0.616 & 0.768 & 0.752 & 0.360 \\
\hline SA-SD & 0.265 & 0.048 & 0.062 & 0.076 & 0.150 \\
\hline
\end{tabular}

\begin{tabular}{|c|c|c|c|c|c|}
\hline $\begin{array}{c}2 \mu M \\
\text { RO3306 }\end{array}$ & $30 \mathrm{~h}$ & $60 \mathrm{~h}$ & $90 \mathrm{~h}$ & $120 \mathrm{~h}$ & $140 \mathrm{~h}$ \\
\hline E-WT & 0.340 & 0.132 & 0.125 & 0.088 & 0.033 \\
\hline E-SA & 0.006 & 0.026 & 0.016 & 0.020 & 0.007 \\
\hline E-SD & 0.889 & 0.604 & 0.381 & 0.890 & 0.542 \\
\hline WT-SA & 0.419 & 0.431 & 0.256 & 0.316 & 0.297 \\
\hline WT-SD & 0.402 & 0.092 & 0.075 & 0.107 & 0.091 \\
\hline SA-SD & 0.068 & 0.042 & 0.044 & 0.048 & 0.031 \\
\hline
\end{tabular}



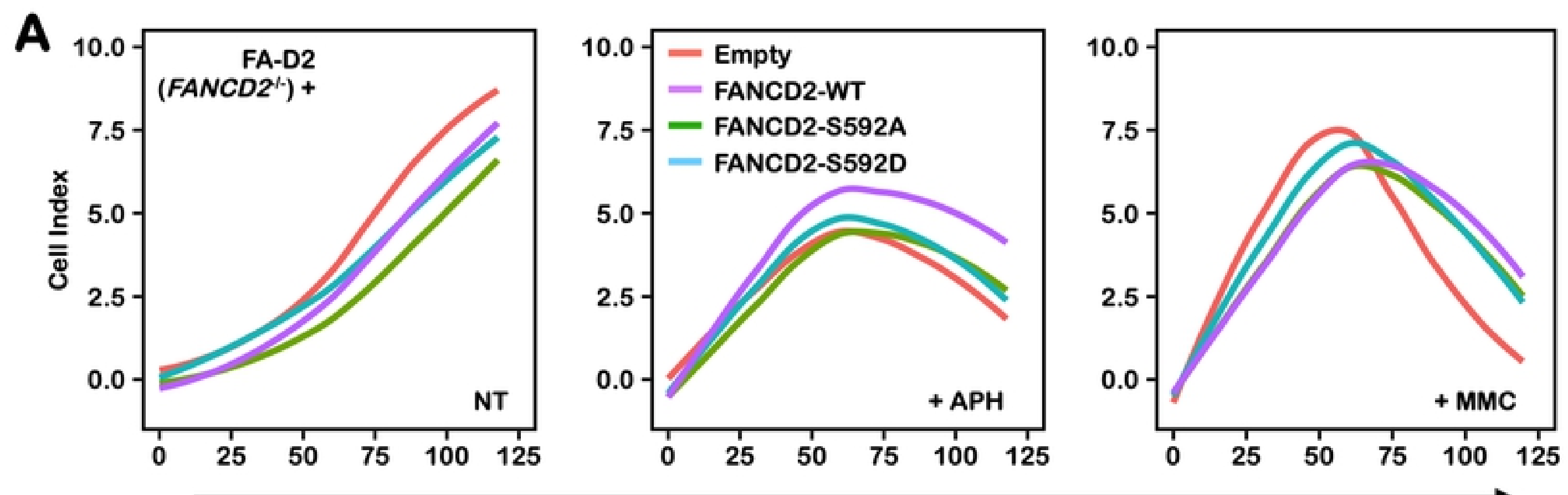

Time (h)
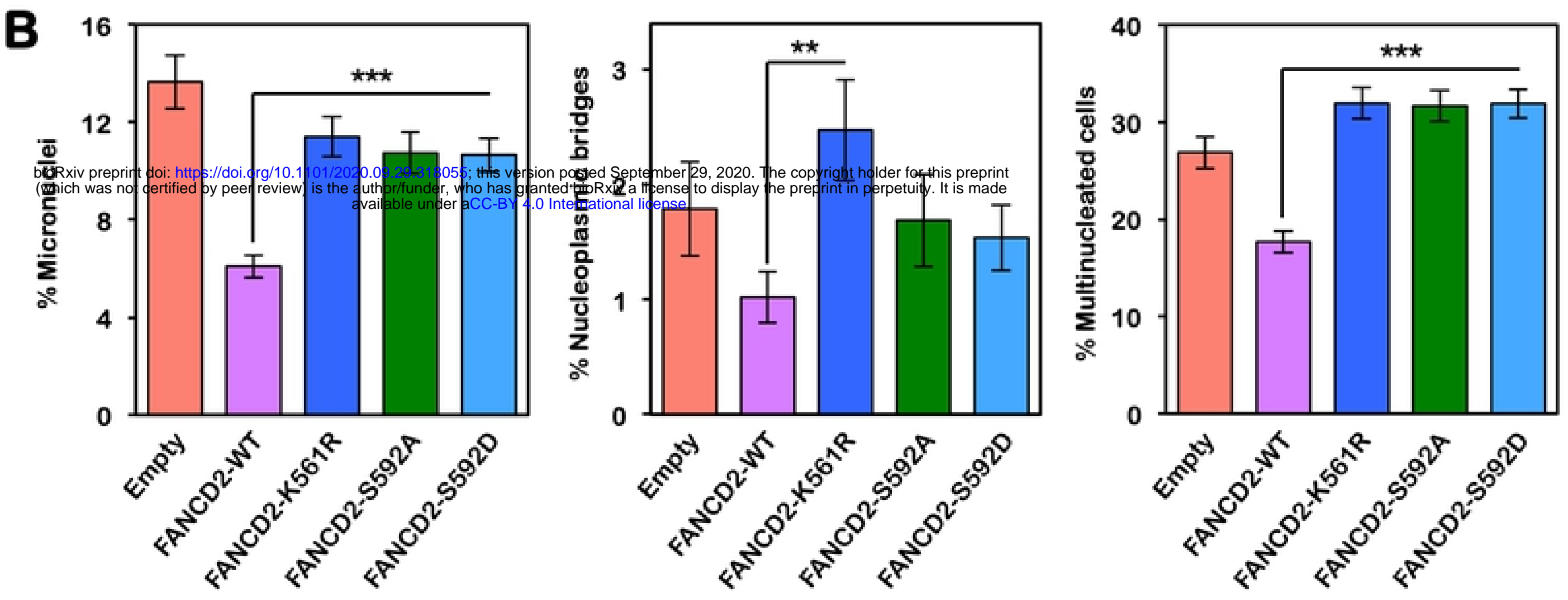

FA-D2

$\left(\right.$ FANCD2 $\left.{ }^{+}\right)+$

Cell line

Figure 5

Figure 5 
A

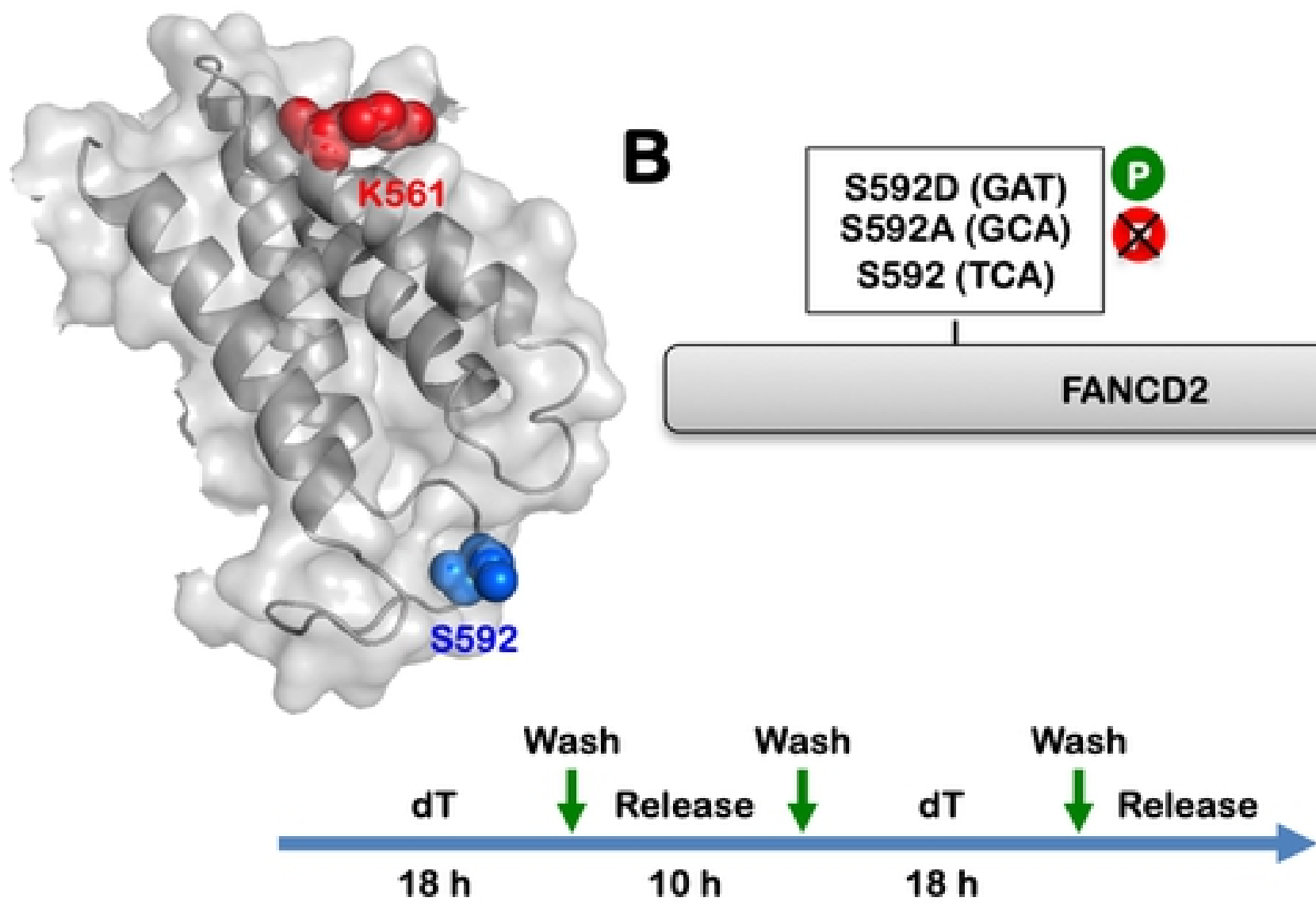

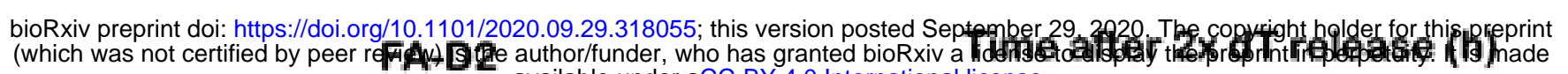
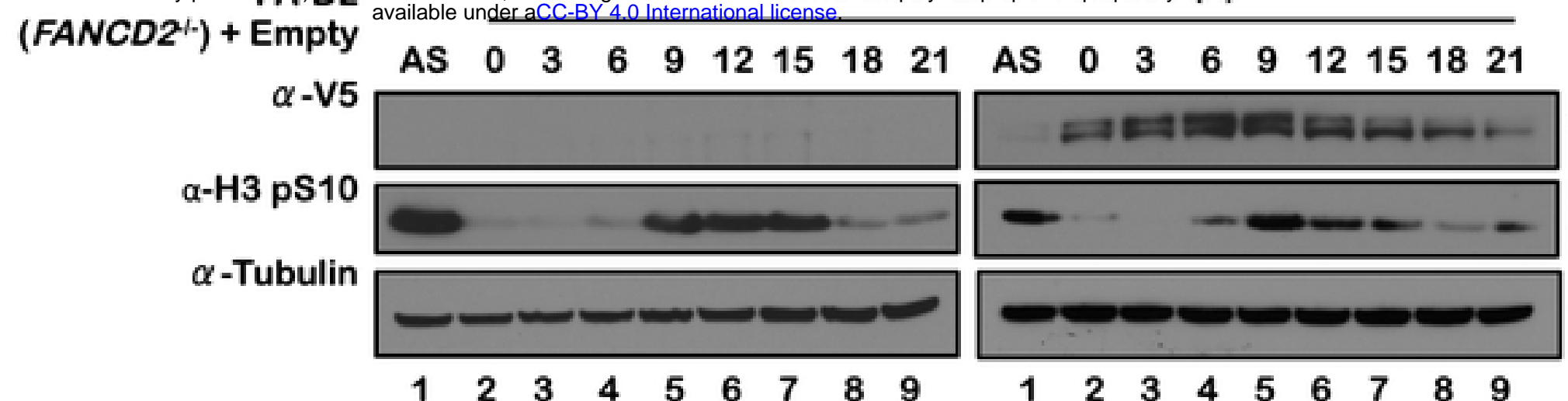

FA-D2

+ FANCD2-WT

FA-D2

+ FANCD2-S592A

$\begin{array}{llllllllll}A & \text { AS } & 0 & 3 & 6 & 9 & 12 & 15 & 18 & 21\end{array}$

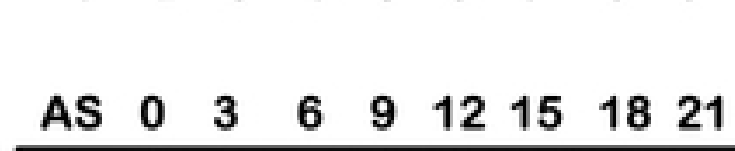

FA-D2 FANCD2-V5-Ub FANCD2-V5
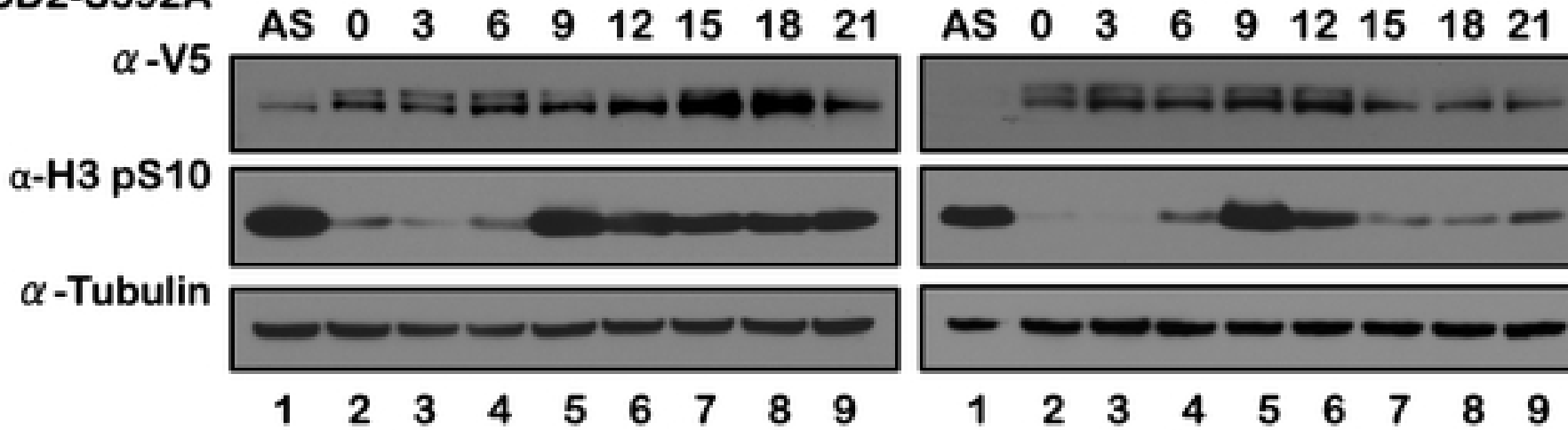

+ FANCD2-S592D

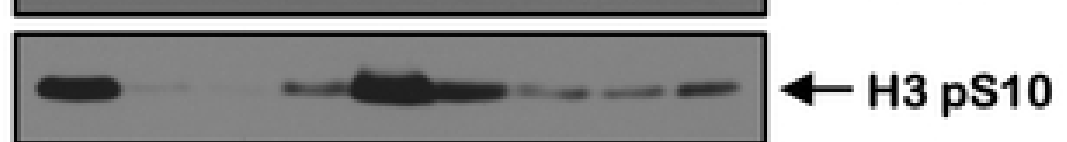

$\begin{array}{lllllllll}1 & 2 & 3 & 4 & 5 & 6 & 7 & 8 & 9\end{array}$

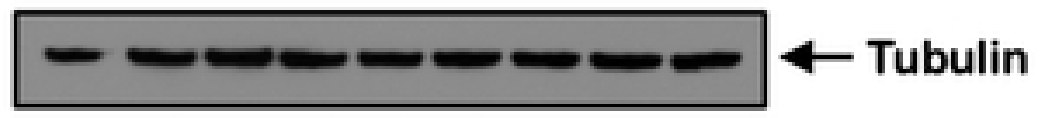




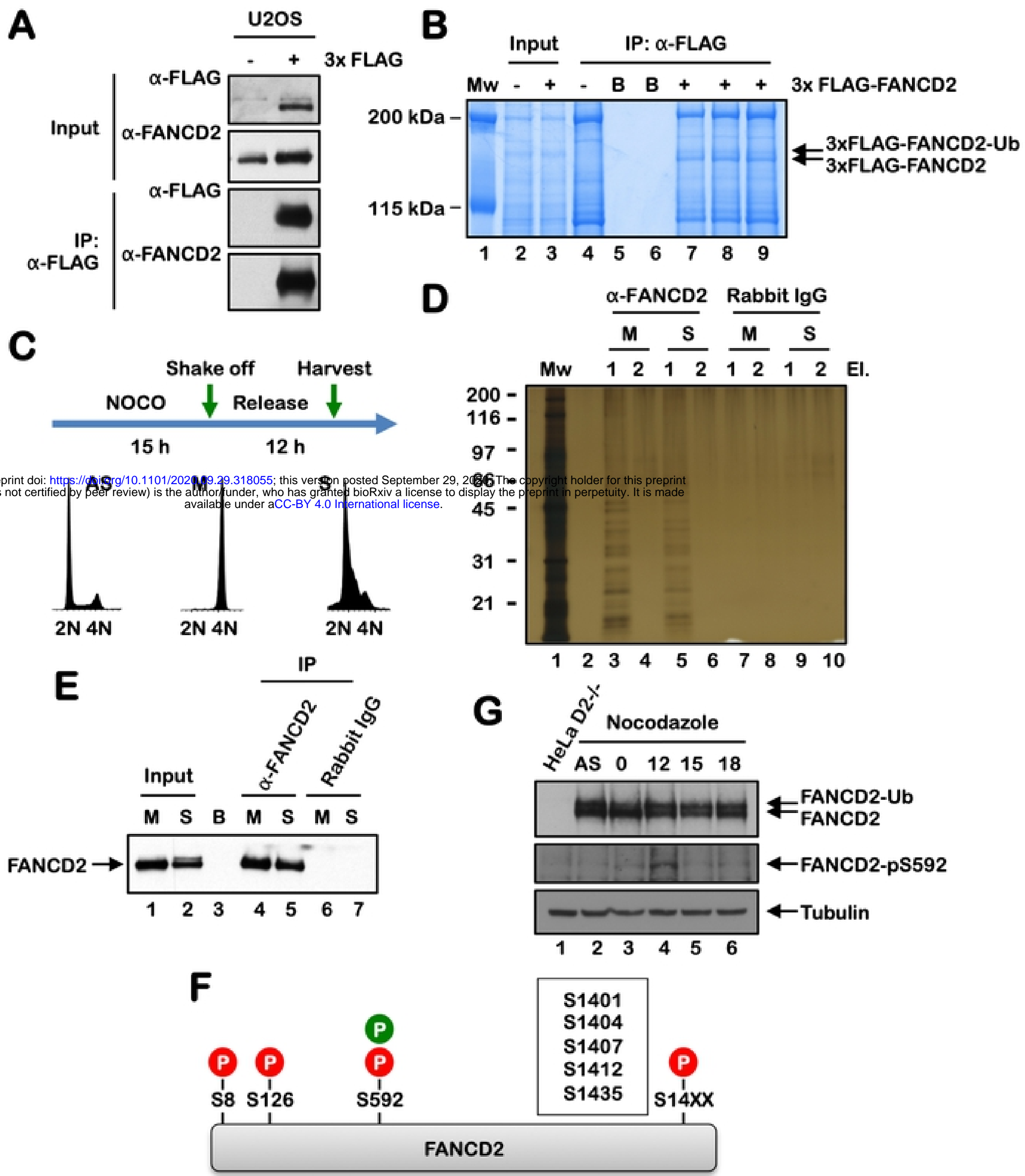



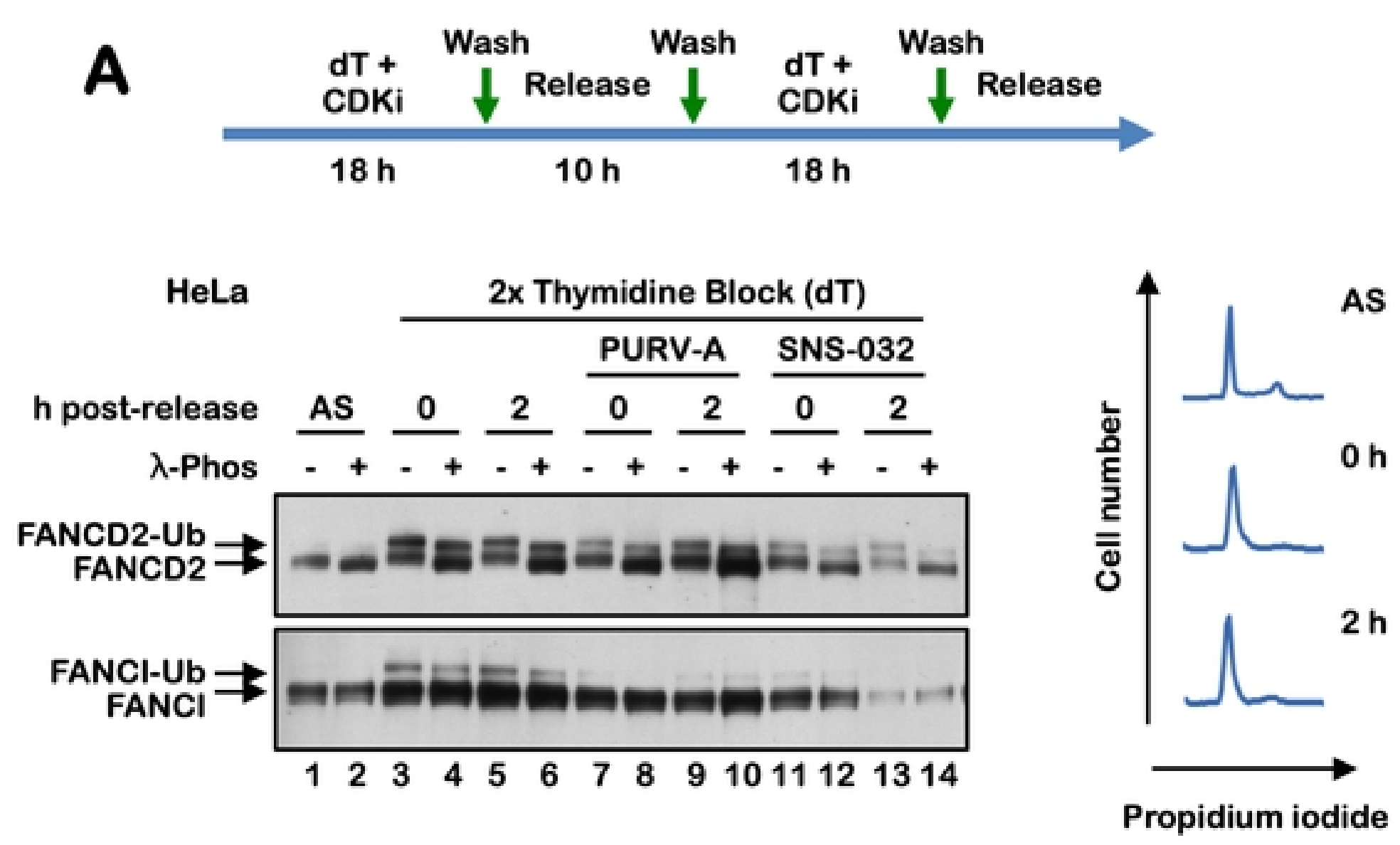

bioRxiv preprint doi: https://d g/10.1101/2020.09.29.318055; this version posted Sedember 29, 2020. Tacopyright holder for this preprint

(which was not certified by $\mathrm{P}$ en eview) is the author/funder, who has granted bioRxinka license to display (he preprint in perpetuity. It is made CDK2-Cyclin A
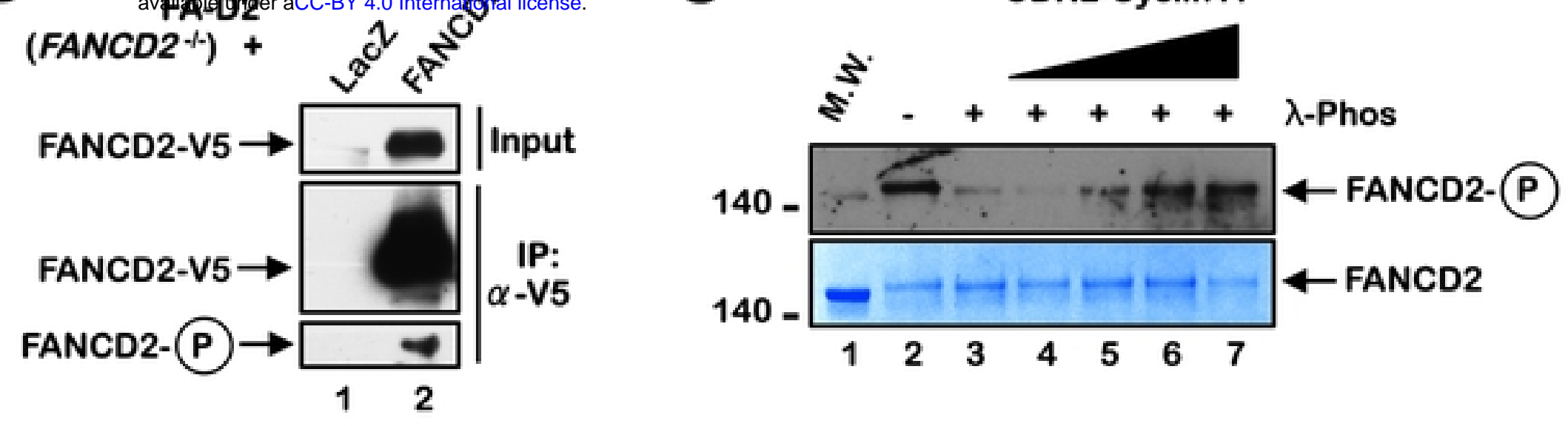
A

$\frac{\text { HeLa }}{-\cdot++\cdots++\cdots++ \text { U2OS }} \frac{\text { COS-7 }}{-\cdot+\text { MMC }}$

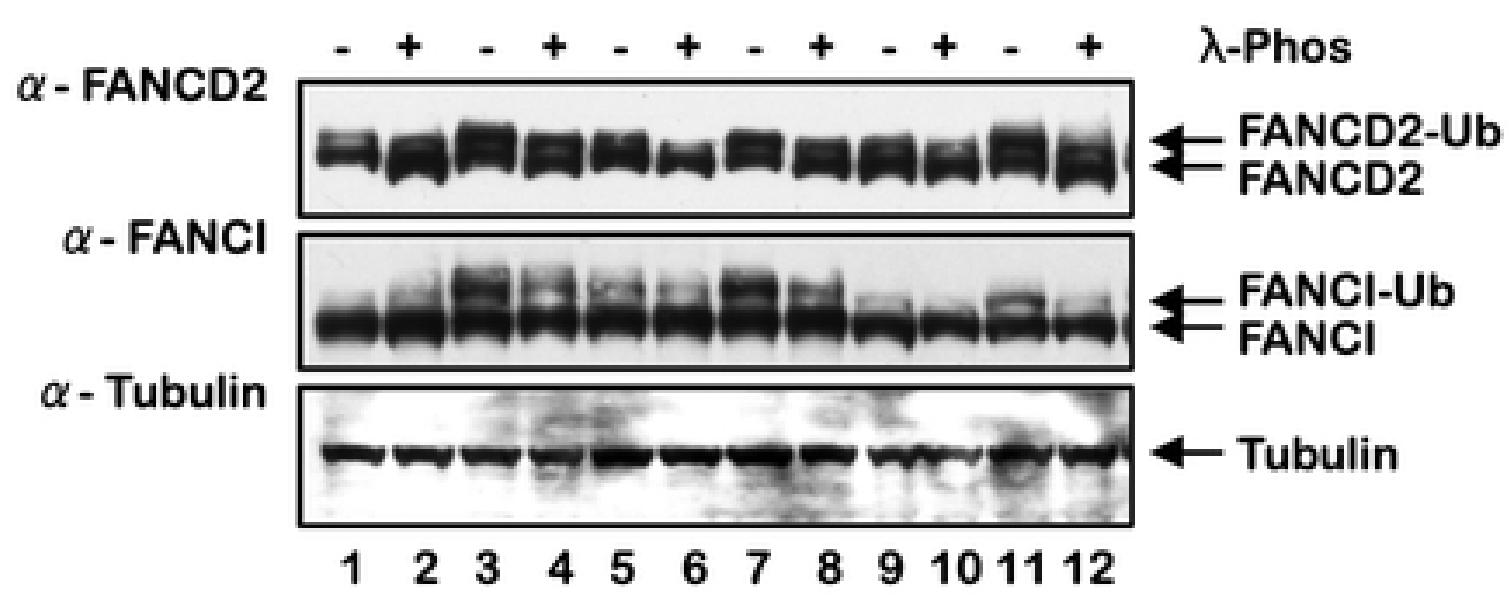

B

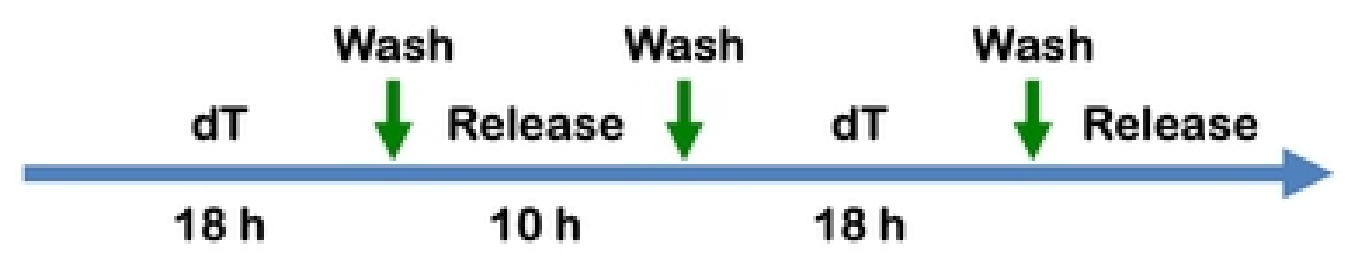

HeLa

2x Thymidine Block (dT)

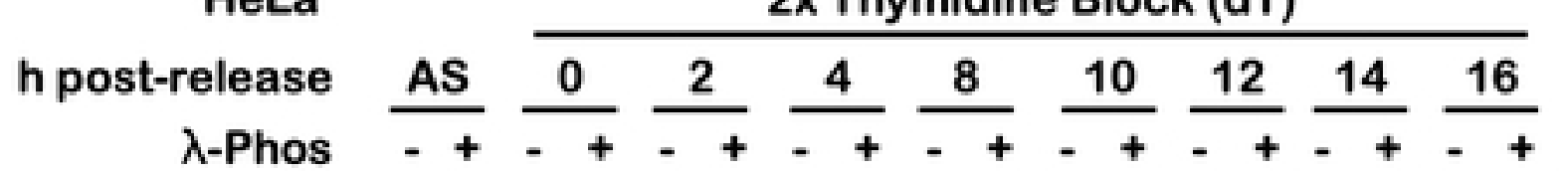

\section{FANCD2-Ub}

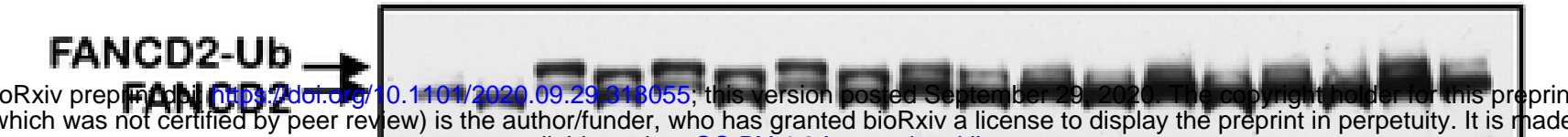

(which was nof certiffed by peer reyjew) is the author/funder, who has granted bioRxiv a license to display the preprint in perpetuity. It is phald
available under aCC-BY 4.0 International license.
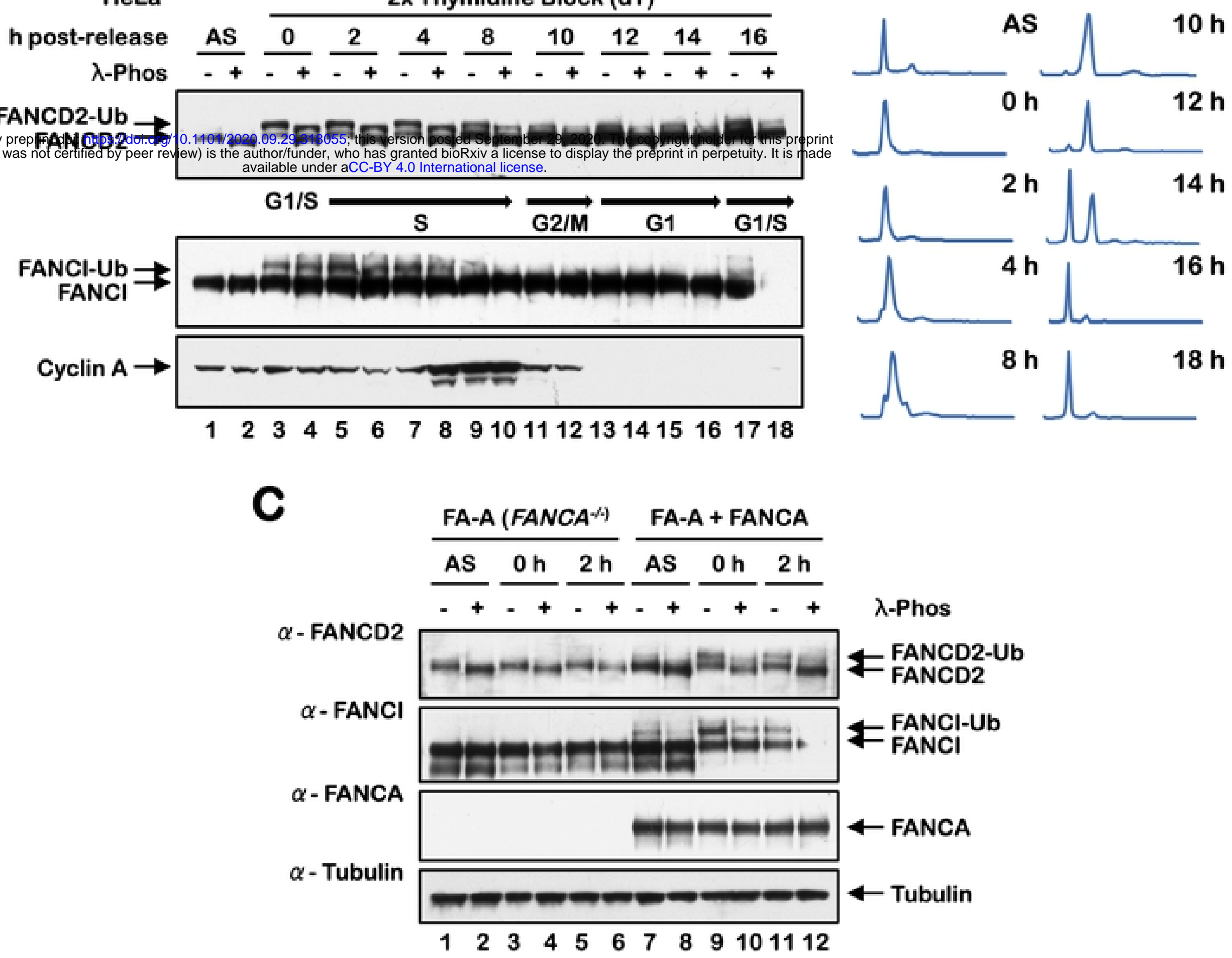